\title{
Electrical Unsteady MHD Natural Convection Flow of Nanofluid with Thermal Stratification and Heat Generation/Absorption
}

\author{
${ }^{1}$ Yahaya Shagaiya Daniel, ${ }^{2}$ Zainal Abdul Aziz, ${ }^{3}$ Zuhaila Ismail* and ${ }^{4}$ Faisal Salah \\ ${ }^{1,2,3}$ Department of Mathematical Sciences, Faculty of Science \\ Universiti Teknologi Malaysia, 81310 UTM Johor Bahru, Johor, Malaysia \\ ${ }^{1,2,3}$ UTM Centre for Industrial and Applied Mathematics (UTM-CIAM) \\ Universiti Teknologi Malaysia, 81310 UTM Johor Bahru, Johor, Malaysia \\ ${ }^{4}$ Department of Mathematics, Faculty of Science \\ University of Kordofan, Elobied, 51111, Sudan \\ *Corresponding author: zuhaila@utm.my
}

Article history

Received: 9 November 2017

Received in revised form: 26 November 2017

Accepted: 4 December 2017

Published on line: 1 December 2018

\begin{abstract}
Analyzed the effects of thermal radiation, chemical reaction, heat generation/absorption, magnetic and electric fields on unsteady flow and heat transfer of nanofluid. The transport equations used passively controlled. A similarity solution is employed to transformed the governing equations from partial differential equations to a set of ordinary differential equations, and then solve using Keller box method. It was found that the temperature is a decreasing function with the thermal stratification due to the fact the density of the fluid in the lower vicinity is much higher compared to the upper region, whereas the thermal radiation, viscous dissipation and heat generation enhanced the nanofluid temperature and thermal layer thickness.
\end{abstract}

Keywords MHD nanofluid; thermal radiation; electric field; heat generation/absorption; chemical reaction.

\section{Mathematics Subject Classification 076, 080, 035}

\section{Introduction}

Magnetic nanofluid analyzes the flow of electrically conducting fluids, for example, salt water, liquid metals, and plasmas. The magnetic field causes current dynamics in a liquid and generates forces on the liquid. Nanofluids are prepared by dispersing ultra-fine solid nanoparticles in conventional fluids such as water, oil, ethylene glycol [1]. This tiny size and low volume fraction of ultrafine solid particles required for thermal conductivity enhancement. The thermal conductivity of these fluids plays a key role in the heat transfer coefficient, so different techniques have been adopted to enhance the thermal conductivity of these fluids. Magnetic field plays an essential role due to applications in medicine, physics, and engineering. Numerous equipment's like magnetohydrodynamics (MHD) generators, pumps, bearing and boundary 
layer control is significantly exaggerated by the interaction between the electrically conducting fluid and a magnetic field [2-4]. The behavior of the movement greatly lies in the orientation and intensity of the applied magnetic field. The applied magnetic field manipulates the dilute suspended nanoparticles and rearranges their concentration in the liquid which greatly changes heat transfer features of the flow behavior. Buongiorno [5] has conducted a study attributed to the factors due to the abnormal increase in the thermal conductivity relative to conventional fluids and viscosity. His developed model for convective transport in nanofluids incorporated Brownian diffusion and thermophoresis effects. The effects of a magnetic field in the presence of Brownian diffusion and thermophoresis can be checked in [6-11] and other applications in many aspects as presented in [12-17].

Thermal radiation impacts have a key role in the areas of science and engineering as result of industrial processes. These are employed at an extreme temperature under various conditions and in a case of smaller convective heat transfer coefficients. Some of the equipment specially used in the design with radiative heat include the model of pertinent, hypersonic flights, nuclear reactors, nuclear power plants, space vehicles, gas turbines. Considering thermal radiation effects on MHD flow model are relevant in the Astrophysical ground, electrical power generation, re-entry space vehicles, solar power technology etc. Stratification is an essential aspect of heat and mass transfer and it has been studied by different investigators [10, 18-21]. It deals with formation or deposition of layers which occur as result of variation in temperature, concentrations or presence of immiscible fluids. The applications involve heat rejection into the system (like rivers, lakes, and seas), thermal energy storage vicinity (solar ponds) and heat transfer generated from thermal sources (the condensers of power plants) [22-27].

Most of the research on unsteady MHD natural convection flow of nanofluid due to stretching sheet and heat transfer with effects of Brownian motion and thermophoresis do not incorporate the combined impact of thermal radiation, thermal stratification, electrical field, chemical reaction and viscous dissipation with the aids of revised nanofluid model Kuznetsov and Nield [28] has not being considered by any researcher. Due to motivation on the need to crisp the understanding of the combined effects of thermodynamic analysis, this analysis is carried out in order to enhance the system performance, with the aforementioned used as a source of unsteady electrical MHD natural convection flow of nanofluid and heat transfer due to a linear permeable stretching sheet with water based nanofluid is used which is a novel. Implicit finite difference scheme presented in Cebeci and Bradshaw [29] is employed to solve the problem. The influence of electric and magnetic fields, thermal radiation, thermal stratification, viscous dissipation and chemical reaction are investigated and shown in details. The influence of physical involves parameters on nanofluid for velocity, temperature, and particle concentration has been discussed extensively and presented graphically. Tables for the skin friction, and local Nusselt number are also presented and analyzed. The results obtained are presented and compared with the previous results published in the literature and found to be in good agreement.

\section{Mathematical Formulation}

We consider a two-dimensional unsteady natural convection flow and heat transfer of MHD nanofluid past a permeable stretching sheet in the presence of electric field, thermal radiation, viscous dissipation, heat generation/absorption, and chemical reaction. The Cartesian coordinate system such that $x$ is chosen along the stretching sheet and $y$-axis denotes the nor- 
mal to the stretching sheet, $u$ and $v$ are the velocity components of the fluid in the $x$ and $y$-direction see Figure 1. The flow is due to stretching of the sheet from a slot through two equal and opposite force and thermally radiative. The velocity of the stretching sheet is denoted as $u_{w}(x, t)=b x /(1-a t)$ where $b$ is the stretching rate and $a$ represent the constant having dimension (time $)^{-1}$ such as $(a t<1, a \geq 0)$. In place of time $t>0$, it is assumed that the flow is in steady state, whereas the unsteady fluid flow setting out at $t=0[23,30]$. The boundary layer equations of the fluid flow consist of the continuity equation, the momentum equation, energy equation and concentration equation. The flow equation is formulated based on Maxwell's equation, Ohm's law in the presence of electrical MHD. The magnetic and electric fields obey the Ohm's law define $J=\sigma(E+V \times B)$ where $J$ is the Joule current, $\sigma$ is the electrical conductivity and $V$ represent the fluid velocity. Magnetic and electric fields of strength $B=B_{0} / \sqrt{1-a t}$ and $E=E_{0} / \sqrt{1-a t}$ are applied normal to the flow field $\left(B_{0}\right.$ is the uniform magnetic field intensity and $E_{0}$ is the electric field factor), such that the magnetic Reynolds number is selected small. The induced magnetic field is smaller to the applied magnetic field. Hence the induced magnetic field is absence for small magnetic Reynolds number. Assuming the nanofluid flow to be unsteady two-dimensional boundary layer flow, incorporating Brownian movement for nanofluid and thermophoresis (mass diffusion), the viscous dissipation and heat generation/absorption in the thermal equation and chemical reaction in the concentration equation. The investigation of the nanofluid involved with nanoparticles and liquid. The fluid properties are indicated with subscript $(\rho c)_{f}$ and that of particles properties $(\rho c)_{p}$. Under these assumptions and employing Oberbeck-Boussinesq approximation [7, 31], the unsteady MHD natural convection model governing the flow, heat and mass transfer are given:

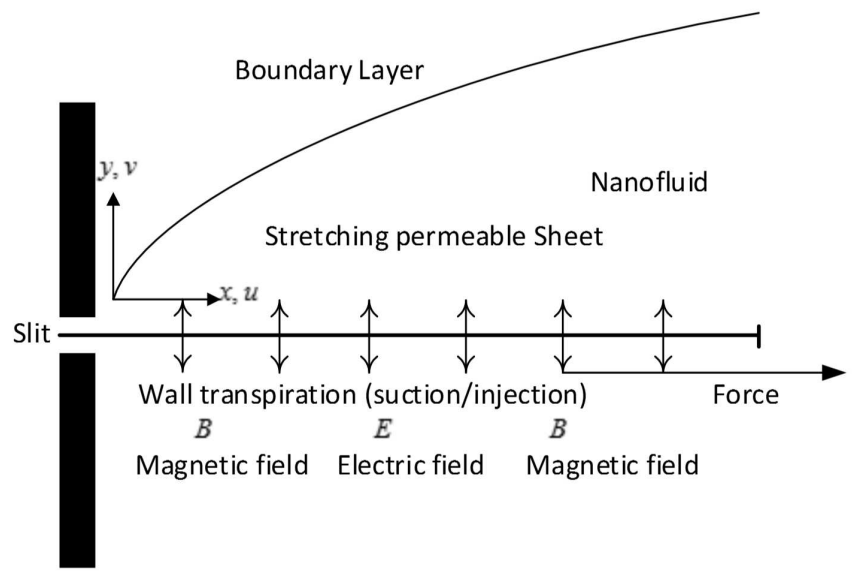

Figure 1: Physical Model and the Co-ordinate System of the Problem

Continuity equation

$$
\frac{\partial u}{\partial x}+\frac{\partial v}{\partial y}=0
$$


$x$-momentum equation

$$
\begin{aligned}
\frac{\partial u}{\partial t}+u \frac{\partial u}{\partial x}+v \frac{\partial u}{\partial y}= & -\frac{1}{\rho_{f}} \frac{\partial p}{\partial x}+v\left(\frac{\partial^{2} u}{\partial x^{2}}+\frac{\partial^{2} u}{\partial y^{2}}\right)+\frac{\sigma}{\rho_{f}}\left(E B-B^{2} u\right) \\
& +\frac{1}{\rho_{f}}\left[\left(1-\varphi_{\infty}\right) \rho_{f \infty} \beta_{T}\left(T-T_{\infty}\right)+\left(\rho_{p}-\rho_{f}\right) \beta_{\varphi}\left(\varphi-\varphi_{\infty}\right)\right] g
\end{aligned}
$$

$y$-momentum equation

$$
\frac{\partial v}{\partial t}+u \frac{\partial v}{\partial x}+v \frac{\partial v}{\partial y}=-\frac{1}{\rho_{f}} \frac{\partial p}{\partial y}+v\left(\frac{\partial^{2} v}{\partial x^{2}}+\frac{\partial^{2} v}{\partial y^{2}}\right)
$$

Energy equation

$$
\begin{aligned}
\frac{\partial T}{\partial t}+u \frac{\partial T}{\partial x}+v \frac{\partial T}{\partial y}=\frac{k}{(\rho c)_{f}} & \left(\frac{\partial^{2} T}{\partial x^{2}}+\frac{\partial^{2} T}{\partial y^{2}}\right) \\
+ & \tau\left\{D_{B}\left(\frac{\partial \varphi}{\partial x} \frac{\partial T}{\partial x}+\frac{\partial \varphi}{\partial y} \frac{\partial T}{\partial y}\right)+\frac{D_{T}}{T_{\infty}}\left[\left(\frac{\partial T}{\partial x}\right)^{2}+\left(\frac{\partial T}{\partial y}\right)^{2}\right]\right\} \\
+ & \frac{\mu}{(\rho c)_{f}}\left(\frac{\partial u}{\partial y}\right)^{2}+\frac{Q}{(\rho c)_{f}}\left(T-T_{\infty}\right)-\frac{1}{(\rho c)_{f}} \frac{\partial q_{r}}{\partial y}
\end{aligned}
$$

Concentration equation

$$
\frac{\partial \varphi}{\partial t}+u \frac{\partial \varphi}{\partial x}+v \frac{\partial \varphi}{\partial y}=D_{B}\left(\frac{\partial^{2} \varphi}{\partial x^{2}}+\frac{\partial^{2} \varphi}{\partial y^{2}}\right)+\frac{D_{T}}{T_{\infty}}\left(\frac{\partial^{2} T}{\partial x^{2}}+\frac{\partial^{2} T}{\partial y^{2}}\right)-k_{1}\left(\varphi-\varphi_{\infty}\right)
$$

The boundary conditions at the sheet for the physical model are presented by

$$
\begin{aligned}
& y=0: u=u_{w}(x, t), \quad v=v_{w}, T=T_{w}(x, t)=T_{0}+A_{1} x(1-a t)^{-1}, D_{B} \frac{\partial \varphi}{\partial y}+\frac{D_{T}}{T_{\infty}} \frac{\partial T}{\partial y}=0, \\
& y \rightarrow \infty: \quad u \rightarrow 0, \quad T \rightarrow T_{\infty}=T_{0}+A_{2} x(1-a t)^{-1}, \quad \varphi \rightarrow \varphi_{\infty},
\end{aligned}
$$

Here $v_{w}(t)=-v_{0} / \sqrt{1-a t}$ is the wall mass transfer, when $v_{w}(t)<0$ denote the injection while $v_{w}(t)>0$ indicates the suction. $u$ and $v$ represent the velocity components along the $x$ and $y$-axis, $A_{1}$ and $A_{2}$ are the dimensional constants with dimension $L^{-1}$ respectively, $p, \alpha=k /(\rho c)_{f}, \mu, \rho, \rho_{f}$, and $\rho_{p}$ are for the fluid pressure, thermal diffusivity (ratio of thermal conductivity to the heat capacity of the fluid), the kinematic viscosity, the density, the fluid density and particles density respectively. We also have $D_{B}, D_{T}, \tau=(\rho c)_{p}(\rho c)_{f}$ which represents the Brownian diffusion coefficient, the thermophoresis diffusion coefficient, the ratio between the effective heat transfer capacity of the ultrafine nanoparticle material and the heat capacity of the fluid and $k_{1}=k_{0} /(1-a t), Q=Q_{0} /(1-a t)$ are the rate of chemical reaction and heat generation, absorption $\left(Q_{0}\right.$ is the heat generation or absorption coefficient and $k_{0}$ is the chemical reaction coefficient) respectively. The radiative heat flux $q_{r}$ via Rosseland approximation $[30,32]$ is applied to equation (4), such that

$$
q_{r}=-\frac{4 \sigma^{*}}{3 k^{*}} \frac{\partial T^{4}}{\partial y}
$$


Where $\sigma^{*}$ represent the Stefan-Boltzmann constant and $k^{*}$ denote the mean absorption coefficient. Expanding $T^{4}$ by using Taylor's series about $T_{\infty}$ and neglecting higher order terms, we have,

$$
T^{4} \cong 4 T_{\infty}^{3} T-3 T_{\infty}^{4}
$$

Using equation (8) into equation (7), we get

$$
\frac{\partial q_{r}}{\partial y}=-\frac{16 T_{\infty}^{3} \sigma^{*}}{3 k^{*}} \frac{\partial^{2} T}{\partial y^{2}}
$$

Use equation (9) in equation (4), we obtain

$$
\begin{aligned}
\frac{\partial T}{\partial t}+u \frac{\partial T}{\partial x}+v \frac{\partial T}{\partial y}= & \frac{k}{(\rho c)_{f}}\left(\frac{\partial^{2} T}{\partial x^{2}}+\frac{\partial^{2} T}{\partial y^{2}}\right) \\
+ & \tau\left\{D_{B}\left(\frac{\partial \varphi}{\partial x} \frac{\partial T}{\partial x}+\frac{\partial \varphi}{\partial y} \frac{\partial T}{\partial y}\right)+\frac{D_{T}}{T_{\infty}}\left[\left(\frac{\partial T}{\partial x}\right)^{2}+\left(\frac{\partial T}{\partial y}\right)^{2}\right]\right\} \\
& +\frac{\mu}{(\rho c)_{f}}\left(\frac{\partial u}{\partial y}\right)^{2}+\frac{Q}{(\rho c)_{f}}\left(T-T_{\infty}\right)+\frac{1}{(\rho c)_{f}}\left(\frac{16 T_{\infty}^{3} \sigma^{*}}{3 k^{*}} \frac{\partial^{2} T}{\partial y^{2}}\right)
\end{aligned}
$$

equation which is normal to the stretching sheet and boundary layer approximation Ibrahim and Shankar [33], such as

$$
\begin{aligned}
u & >> \\
\frac{\partial u}{\partial y} & >>\frac{\partial u}{\partial x}, \frac{\partial v}{\partial t}, \frac{\partial v}{\partial x}, \frac{\partial v}{\partial y} \\
\frac{\partial p}{\partial y} & =0 .
\end{aligned}
$$

After the analysis, the boundary layer equations (1) - (5) are reduced to the following as:

$$
\begin{aligned}
\frac{\partial u}{\partial x}+\frac{\partial v}{\partial y}= & 0 \\
\frac{\partial u}{\partial t}+u \frac{\partial u}{\partial x}+v \frac{\partial u}{\partial y}=\nu \frac{\partial^{2} u}{\partial y^{2}}+\frac{\sigma}{\rho_{f}}\left(E B-B^{2} u\right) & +\frac{1}{\rho_{f}}\left[\left(1-\varphi_{\infty}\right) \rho_{f \infty} \beta_{T}\left(T-T_{\infty}\right)+\left(\rho_{p}-\rho_{f}\right) \beta_{\varphi}\left(\varphi-\varphi_{\infty}\right)\right] g \\
\frac{\partial T}{\partial t}+u \frac{\partial T}{\partial x}+v \frac{\partial T}{\partial y}= & \frac{k}{(\rho c)_{f}}\left(\frac{\partial^{2} T}{\partial y^{2}}\right)+\tau\left\{D_{B}\left(\frac{\partial \varphi}{\partial y} \frac{\partial T}{\partial y}\right)+\frac{D_{T}}{T_{\infty}}\left[\left(\frac{\partial T}{\partial y}\right)^{2}\right]\right\} \\
& +\frac{\mu}{(\rho c)_{f}}\left(\frac{\partial u}{\partial y}\right)^{2}+\frac{Q}{(\rho c)_{f}}\left(T-T_{\infty}\right)+\frac{1}{(\rho c)_{f}}\left(\frac{16 T_{\infty}^{3} \sigma^{*}}{3 k^{*}} \frac{\partial^{2} T}{\partial y^{2}}\right) \\
\frac{\partial \varphi}{\partial t}+u \frac{\partial \varphi}{\partial x}+v \frac{\partial \varphi}{\partial y}= & D_{B}\left(\frac{\partial^{2} \varphi}{\partial y^{2}}\right)+\frac{D_{T}}{T_{\infty}}\left(\frac{\partial^{2} T}{\partial y^{2}}\right)-k_{1}\left(\varphi-\varphi_{\infty}\right)
\end{aligned}
$$


The boundary conditions at the sheet for the physical model are presented by

$$
\begin{aligned}
& y=0: u=u_{w}(x, t), \quad v=v_{w}, T=T_{w}(x, t)=T_{0}+A_{1} x(1-a t)^{-1}, \quad D_{B} \frac{\partial \varphi}{\partial y}+\frac{D_{T}}{T_{\infty}} \frac{\partial T}{\partial y}=0, \\
& y \rightarrow \infty: \quad u \rightarrow 0, \quad T \rightarrow T_{\infty}=T_{0}+A_{2} x(1-a t)^{-1}, \quad \varphi \rightarrow \varphi_{\infty} .
\end{aligned}
$$

The equations are reduced into the dimensionless form by introducing the following dimensionless quantities defined as:

$$
\psi=\sqrt{\frac{b v}{1-a t}} x f(\eta), \eta=y \sqrt{\frac{b}{v(1-a t)}}, \theta=\frac{T-T_{\infty}}{T_{w}-T_{\infty}}, \phi=\frac{\varphi-\varphi_{\infty}}{\varphi_{\infty}} .
$$

The stream function $\psi$ can be given as:

$$
u=\frac{\partial \psi}{\partial y}, v=-\frac{\partial \psi}{\partial x} .
$$

Using equations (17) - (18) into equations (12) - (15). The equations of momentum, energy and nanoparticle concentration in dimensionless form become:

$$
\begin{aligned}
f^{\prime \prime \prime}+f f^{\prime \prime}-f^{\prime 2}-\delta\left(f^{\prime}+\frac{\eta}{2} f^{\prime \prime}\right)+M\left(E_{1}-f^{\prime}\right)+\lambda_{T} \theta+\lambda_{M} \phi & =0 \\
\frac{1}{P r}\left(1+\frac{4}{3} R d\right) \theta^{\prime \prime}+f \theta^{\prime}-f^{\prime} \theta-\delta\left(s_{t}+\frac{\eta}{2} \theta^{\prime}+\theta\right)+N b \phi^{\prime} \theta^{\prime} & \\
+N t \theta^{\prime 2}+E c\left(f^{\prime \prime}\right)^{2}+\varepsilon \theta-s_{t} f^{\prime} & =0 \\
\phi^{\prime \prime}+\frac{N t}{N b} \theta^{\prime \prime}+S c f \phi^{\prime}-S c \delta \frac{\eta}{2} \phi^{\prime}-S c \gamma \phi & =0 .
\end{aligned}
$$

The boundary conditions are given by

$$
\begin{aligned}
& f=s, \quad f^{\prime}=1, \quad \theta=1-s_{t}, \quad N b \phi^{\prime}+N t \theta^{\prime}=0, \quad \text { at } \eta=0, \\
& f^{\prime}=0, \quad \theta=0, \quad \phi=0, \text { as } \eta \rightarrow \infty,
\end{aligned}
$$

Here $f^{\prime}, \theta$ and $\phi$ are the dimensionless velocity, temperature, and concentration, respectively, $\delta=a / b$ represent the unsteadiness parameter, $\lambda_{T}=G r / R e^{2}$ is the thermal convective parameter, $R e=u_{w} l / v$ is the Reynolds number, $\lambda_{M}=G m / R e^{2}$ denotes the mass convective parameter, $G r=g \beta_{T}\left(1-\varphi_{\infty}\right)\left(T_{w}-T_{\infty}\right) l^{3} / \nu^{2}$ is the Grashof number, $X=x / l$ is the dimensionless constant, $G m=g \beta_{\varphi}\left(\rho_{p}-\rho_{f}\right) \varphi_{\infty} l^{3} / \nu^{2} \rho_{f}$ is the mass Grashof number, $\operatorname{Pr}=v / \alpha$ stand for Prandtl number, $N b=(\rho c)_{p} D_{B} \varphi_{\infty} /(\rho c)_{f} v$ is the Brownian motion parameter, $S c=v / D_{B}$ is the Schmidt number, $N t=(\rho c)_{p} D_{T}\left(T_{w}-T_{\infty}\right) /(\rho c)_{f} v T_{\infty}$ is the thermophoresis parameter, $M=\sigma B_{0}^{2} / b \rho_{f}$ is the magnetic field parameter, $E_{1}=E_{0} / u_{w} B_{0}$ is the electric field parameter, $E c=u_{w}^{2} / c_{p}\left(T_{w}-T_{\infty}\right)$ is the Eckert number, $s=v_{0} / \sqrt{v b}$ is the suction $(s>0)$ injection $(s<0)$ parameter and $R d=4 \sigma^{*} T_{\infty}^{3} / k^{*} k$ is the radiation parameter, $s_{t}=A_{2} / A_{1}$ denote the thermal stratification parameter, $\varepsilon=Q_{0} / b(\rho c)_{f}$ is the heat generation/absorption as $(\varepsilon>0)$ denotes heat generation and $(\varepsilon<0)$ denotes heat absorption, and $\gamma=k_{0} / b$ is the chemical reaction, for $(\gamma>0)$ associates to destructive chemical reaction while $(\gamma<0)$ corresponds to generative chemical reaction respectively. Where prime represents differentiation with respect 
to $\eta$. In our present study, the selection of non-dimensional embedded parameters of nanofluids is considered to vary in view of the works of [6, 33-35].

The skin friction coefficient and the local Nusselt number are as follows:

$$
c_{f}=\frac{\tau_{w}}{\rho u_{w}^{2}(x, t)}, \quad N u=\frac{x q_{w}}{k\left(T_{w}-T_{\infty}\right)},
$$

where

$$
\tau_{w}=\mu_{f}\left(\frac{\partial u}{\partial y}\right)_{y=0}, \quad q_{w}=-\left(\left(k+\frac{16 \sigma^{*} T_{\infty}^{2}}{3 k^{*}}\right) \frac{\partial T}{\partial y}\right)_{y=0} .
$$

Here $\tau_{w}$ is the shear stress in the stretching surface, $q_{w}$ is the surface heat flux and $k$ is the thermal conductivity of the nanofluid. For the local skin-friction coefficient and local Nusselt number are presented in non-dimensional form as

$$
R e^{1 / 2} c_{f}=f^{\prime \prime}(0), \quad N u / R e^{1 / 2}=-\left(1+\frac{4}{3} R d\right) \theta^{\prime}(0)
$$

\section{Result and Discussion}

The set of highly nonlinear ordinary differential equations (19) - (21) with boundary conditions (22) are solved with the aids of Keller box method for several values of embedded parameters in the equations such as magnetic field $M$, electric field $E_{1}$, suction/injection parameter $s$, thermal convective parameter $\lambda_{T}$, mass convective parameter $\lambda_{M}$, thermal radiation $R d$, Eckert number $E c$, unsteadiness parameter $\delta$, Brownian motion parameter $N b$, thermophoresis parameter $N t$, Schmidt number $S c$, heat generation/absorption $\varepsilon$, and chemical reaction parameter $\gamma$. For the validation of present numerical scheme, the results are presented and examined with Ibrahim and Shankar [33] in some limiting case when $E_{1}=\delta=\lambda_{T}=\lambda_{M}=0$. The numerical values are in good agreement as displayed in Table 1 presents the effects of evolving parameters on the skin friction coefficient. Numerical values of the local Nusselt number for different involving parameters are presented in Table 2. It is noted that the local Nusselt number decreases for higher values of $M, R d, E c, \varepsilon>0, \gamma>0$, and $\lambda_{M}$, conversely, it increases for higher values of $S c, N b, N t, \delta, s_{t}, \gamma<0, s, E_{1}, \varepsilon<0$, and $\lambda_{T}$.

The velocity, temperature, and nanoparticles concentration profiles see Figs 2-19 for various values of parameters such as the electric field $E_{1}$, suction/injection parameter $s$, unsteadiness $\delta$, magnetic field $M$, thermal radiation $R d$, Eckert number $E c$, thermophoresis $N t$, Brownian motion $N b$, Schmidt number $S c$, chemical reaction $\gamma$, thermal convective parameter $\lambda_{T}$, mass convective parameter $\lambda_{M}$, heat generation/absorption $\varepsilon$, and thermal stratification parameter $s_{t}$. The effect of magnetic field parameter $M$ results in a decrease in fluid velocity profile $f^{\prime}(\eta)$. Magnetic field depicts the ratio of hydromagnetic body force to viscous force, an increase in magnetic field parameter leads to a stronger hydromagnetic body force which has a tendency to reduce fluid movement. Hence application of an applied magnetic field is a resourceful mechanism for controlling the nanoparticle fluid movement. Figure 3 is sketched to highlight the effect of electric field parameter $E_{1}$ on the non-dimensional nanofluid velocity profile. It is worth perceiving that velocity of the nanofluid enhances significantly with an increase in electric field parameter $E_{1}$. The reason is that increasing electric field $E_{1}$, resistance between fluid particles increases so that Lorentz force tends to accelerate the body forces and hence leads to increase 
Table 1: Comparison of Skin Friction Coefficient $-f^{\prime \prime}(0)$ When $\lambda_{T}=\lambda_{M}=0$ for Various Values of $M, s, E_{1}$, and $\delta$

\begin{tabular}{|c|c|c|c|c|c|}
\hline$M$ & $s$ & $E_{1}$ & $\delta$ & Ibrahim and Shankar [33] & Present results \\
\hline 0 & 0.5 & 0 & 0 & 1.2808 & 1.280777 \\
\hline 0.5 & & & & 1.5000 & 1.500000 \\
\hline 1.0 & & & & 1.6861 & 1.686141 \\
\hline 1.5 & & & & 1.8508 & 1.850781 \\
\hline 2.0 & & & & 2.0000 & 2.000000 \\
\hline 1.0 & 0 & & & 1.4142 & 1.414214 \\
\hline & 0.2 & & & 1.5177 & 1.517745 \\
\hline & 0.7 & & & 1.8069 & 1.806880 \\
\hline & 1.0 & & & 2.0000 & 2.000000 \\
\hline & 0.2 & 0.1 & & - & 1.335083 \\
\hline & & 0.3 & & - & 1.003660 \\
\hline & & 0.5 & & - & 0.698797 \\
\hline & & 0.1 & 0.2 & - & 1.400699 \\
\hline & & & 0.7 & - & 1.547543 \\
\hline & & & 1.5 & & 1.774626 \\
\hline
\end{tabular}

in the flow of the nanofluid velocity and hence thicker momentum boundary layer. Fig. 4 establishes the impact of suction/injection parameter $s$ on the non-dimensional nanofluid velocity profile $f^{\prime}(\eta)$. In this Fig. it is experiential that the momentum boundary layer thickness reductions with intensification in suction parameter $(s>0)$. As a result of the mass suction, the fluid is approaching to the surface and hence it prevents the vorticity diffusion. The momentum boundary layer thickness becomes thinner and the velocity is reduced. Reversed effects occurred in the case of injection parameter $(s<0)$. The influence of unsteadiness parameter $\delta$ on the non-dimensional nanofluid velocity is revealed in Fig. 5. Increasing values of the unsteadiness parameter designate smaller stretching rate which eventually decreases the nanofluid velocity and momentum boundary layer thickness. Fig. 6 uncovered the influence of thermal convective parameter $\lambda_{T}$ on the non-dimensional nanofluid velocity profile $f^{\prime}(\eta)$. The thermal convective parameter for the flow field demonstrates the relative impact of the thermal buoyancy force to the viscous momentum force in the boundary layer. It is detected that there is an increase in the nanofluid velocity due to the enhancement of thermal buoyancy force. Figure 7 shows the effects of mass convective parameter $\lambda_{M}$ on the non-dimensional nanofluid velocity profile $f^{\prime}(\eta)$. The convective parameter for mass transfer embodies the buoyancy force to the viscous momentum force. As typical, the nanofluid velocity diminutions distinctively as results of an enhancement in the viscous momentum force. The nanofluid velocity distribution reaches a distinctive smallest value in the locality of the stretching sheet. It is noticed that the velocity magnifies with decreasing values of convective parameter for mass transfer.

Fig. 8 depicts the behavior of thermal radiation parameter $R d$ on the non-dimensional temperature profile $\theta(\eta)$. The increment in thermal radiation parameter results in an enhancement 
Table 2: Numerical Values for Local Nusselt Number when $\operatorname{Pr}=6.2$ for Different Values of $M, R d, E c, S c, N b, N t, E_{1}, \gamma, s, \delta, \lambda_{T}, \lambda_{M}, s_{t}$, and $\varepsilon$

\begin{tabular}{|c|c|c|c|c|c|c|c|c|c|c|c|c|c|c|}
\hline$M$ & $R d$ & $E c$ & $S c$ & $\mathrm{Nb}$ & $N t$ & $E_{1}$ & $\gamma$ & $s$ & $\delta$ & $\lambda_{T}$ & $\lambda_{M}$ & $s_{t}$ & $\varepsilon$ & $-\left(1+\frac{4}{3} R d\right) \theta^{\prime}(0)$ \\
\hline 0.1 & 0.2 & 0.1 & 1.5 & 0.2 & 0.1 & 0.1 & 0.1 & 0.1 & 0.1 & 0.2 & 0.1 & 0.1 & 0.1 & 2.824002 \\
\hline 0.5 & & & & & & & & & & & & & & 2.784553 \\
\hline 1.0 & & & & & & & & & & & & & & 2.738007 \\
\hline 0.1 & 0.4 & & & & & & & & & & & & & 2.523965 \\
\hline & $\overline{0.6}$ & & & & & & & & & & & & & 2.296389 \\
\hline & 1.0 & & & & & & & & & & & & & 1.969363 \\
\hline & 0.2 & 0.2 & & & & & & & & & & & & 2.704594 \\
\hline & & 0.4 & & & & & & & & & & & & 2.467419 \\
\hline & & 0.8 & & & & & & & & & & & & 1.999549 \\
\hline & & 0.1 & 1.7 & & & & & & & & & & & 2.829751 \\
\hline & & & 5.0 & & & & & & & & & & & 2.903472 \\
\hline & & & 10 & & & & & & & & & & & 2.975645 \\
\hline & & & 1.5 & 0.1 & & & & & & & & & & 2.811417 \\
\hline & & & & 0.3 & & & & & & & & & & 2.828431 \\
\hline & & & & 0.4 & & & & & & & & & & 2.830671 \\
\hline & & & & 0.2 & 0.2 & & & & & & & & & 2.863585 \\
\hline & & & & & 0.3 & & & & & & & & & 2.905399 \\
\hline & & & & & 0.4 & & & & & & & & & 2.953178 \\
\hline & & & & & 0.1 & 0.2 & & & & & & & & 2.831726 \\
\hline & & & & & & 0.5 & & & & & & & & 2.858938 \\
\hline & & & & & & 1.0 & & & & & & & & 2.901846 \\
\hline & & & & & & 0.1 & -0.1 & & & & & & & 2.827327 \\
\hline & & & & & & & -1.0 & & & & & & & 2.660728 \\
\hline & & & & & & & 1.0 & & & & & & & 2.829533 \\
\hline & & & & & & & 0.1 & $\overline{0.2}$ & & & & & & 3.141008 \\
\hline & & & & & & & & 0.3 & & & & & & 3.476122 \\
\hline & & & & & & & & 0.4 & & & & & & 3.827053 \\
\hline & & & & & & & & 0.1 & 0.2 & & & & & 2.949185 \\
\hline & & & & & & & & & 0.3 & & & & & 3.036321 \\
\hline & & & & & & & & & 0.5 & & & & & 3.130515 \\
\hline & & & & & & & & & 0.1 & 0.5 & & & & 2.902639 \\
\hline & & & & & & & & & & 1.0 & & & & 3.009461 \\
\hline & & & & & & & & & & 1.5 & & & & 3.086433 \\
\hline & & & & & & & & & & 0.5 & 0.2 & & & 2.889889 \\
\hline & & & & & & & & & & & 0.3 & & & 2.876898 \\
\hline & & & & & & & & & & & 0.4 & & & 2.863809 \\
\hline & & & & & & & & & & & 0.1 & 0.2 & & 2.887425 \\
\hline & & & & & & & & & & & & 0.5 & & 2.784005 \\
\hline & & & & & & & & & & & & 0.7 & & 2.610419 \\
\hline & & & & & & & & & & & & 0.1 & -0.5 & 3.253990 \\
\hline & & & & & & & & & & & & & -0.2 & 3.064355 \\
\hline & & & & & & & & & & & & & 0.2 & 2.830488 \\
\hline & & & & & & & & & & & & & 0.5 & 2.679725 \\
\hline
\end{tabular}




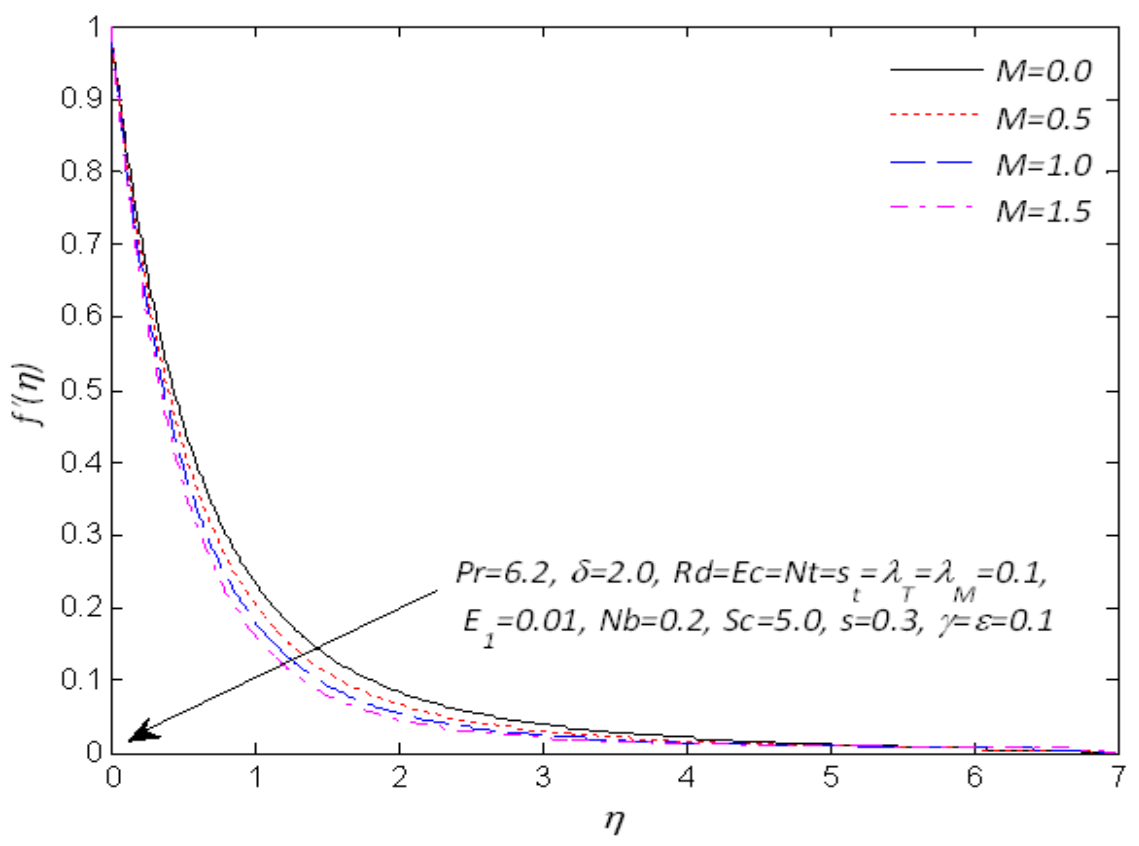

Figure 2: Velocity Profile for Varying $M$

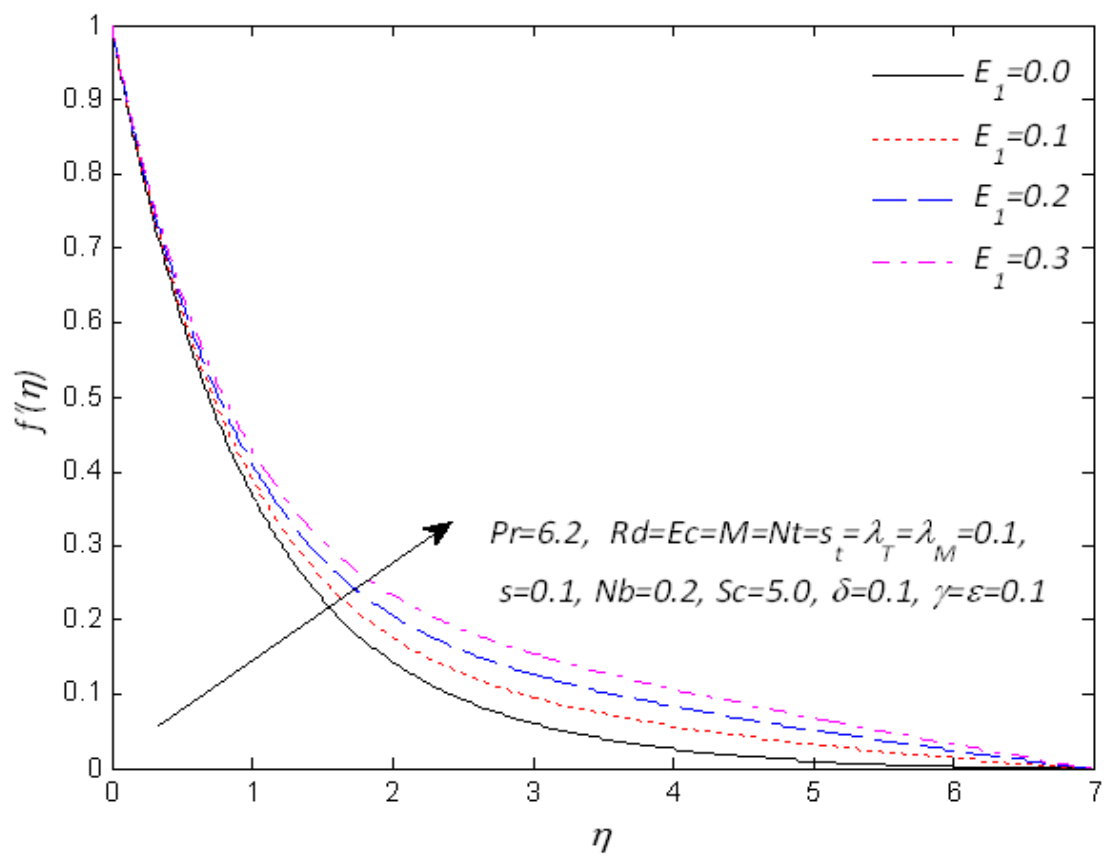

Figure 3: Velocity Profile for Varying $E_{1}$ 


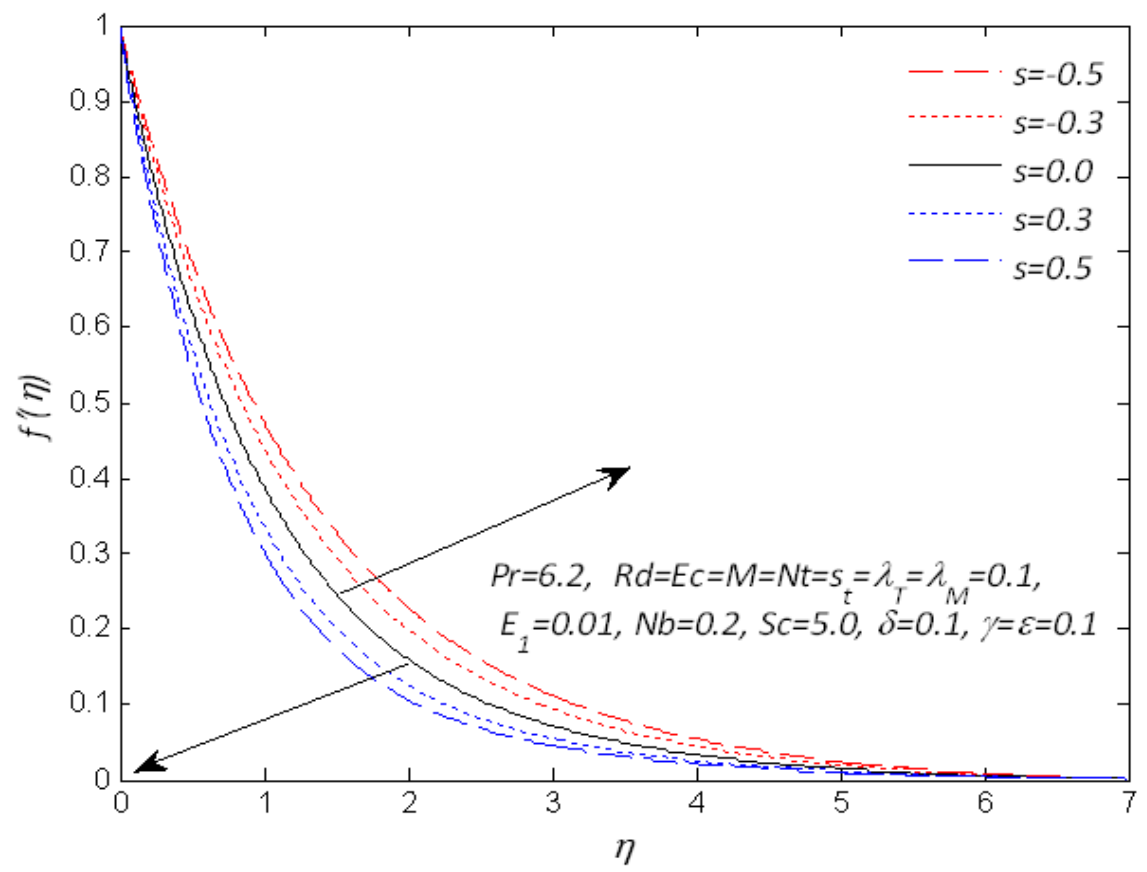

Figure 4: Velocity Profile for Varying $s$

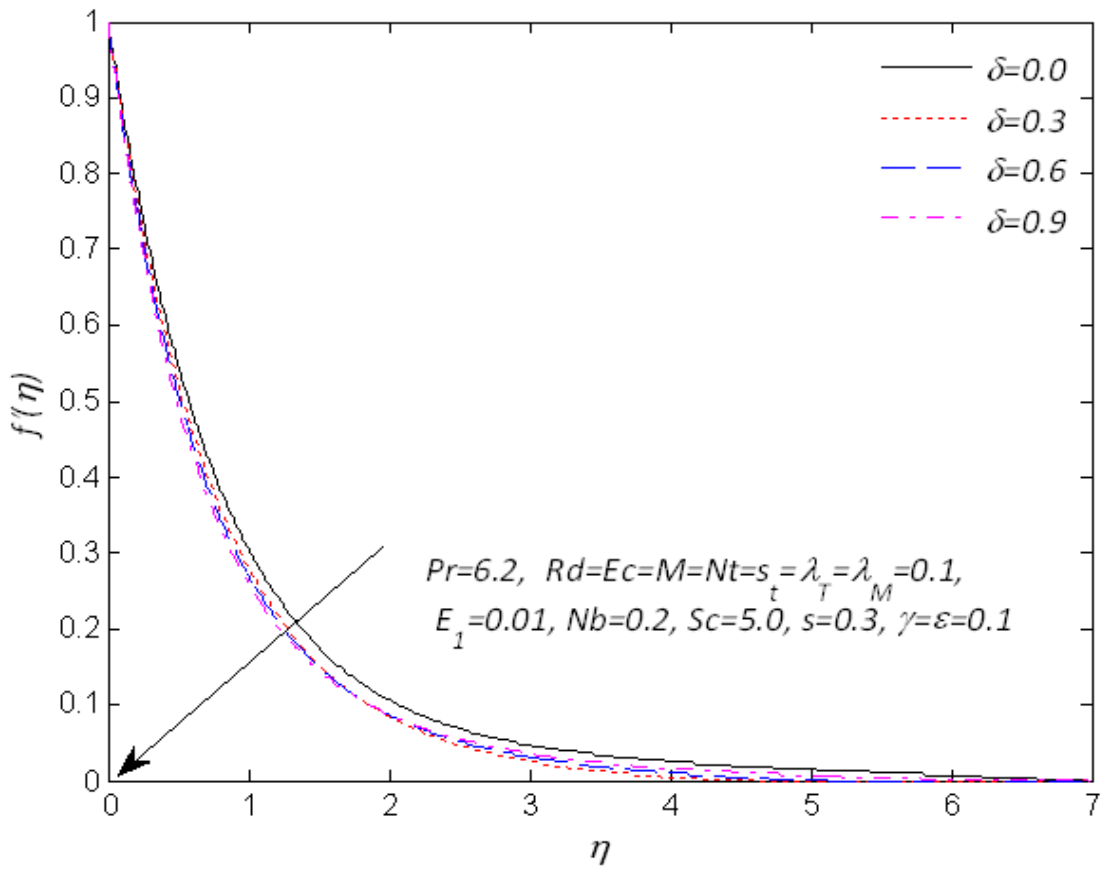

Figure 5: Velocity Profile for Varying $\delta$ 


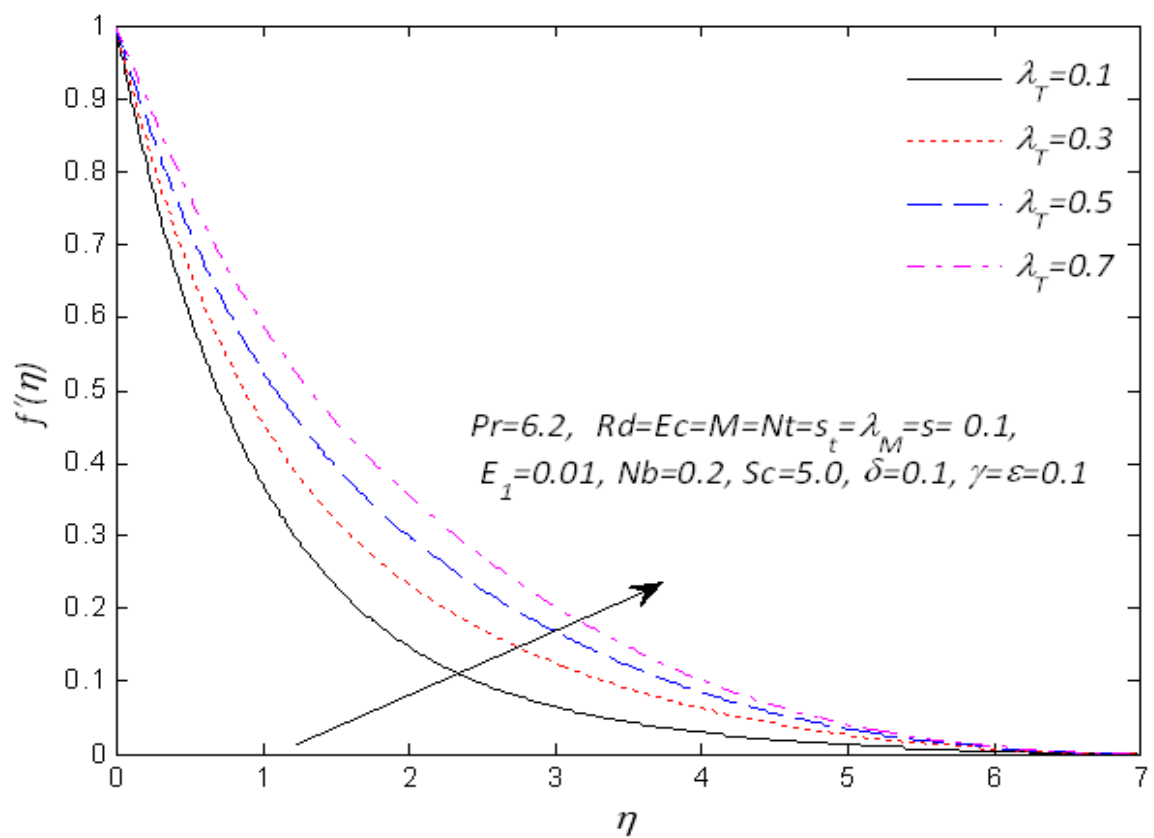

Figure 6: Velocity Profile for Varying $\lambda_{T}$

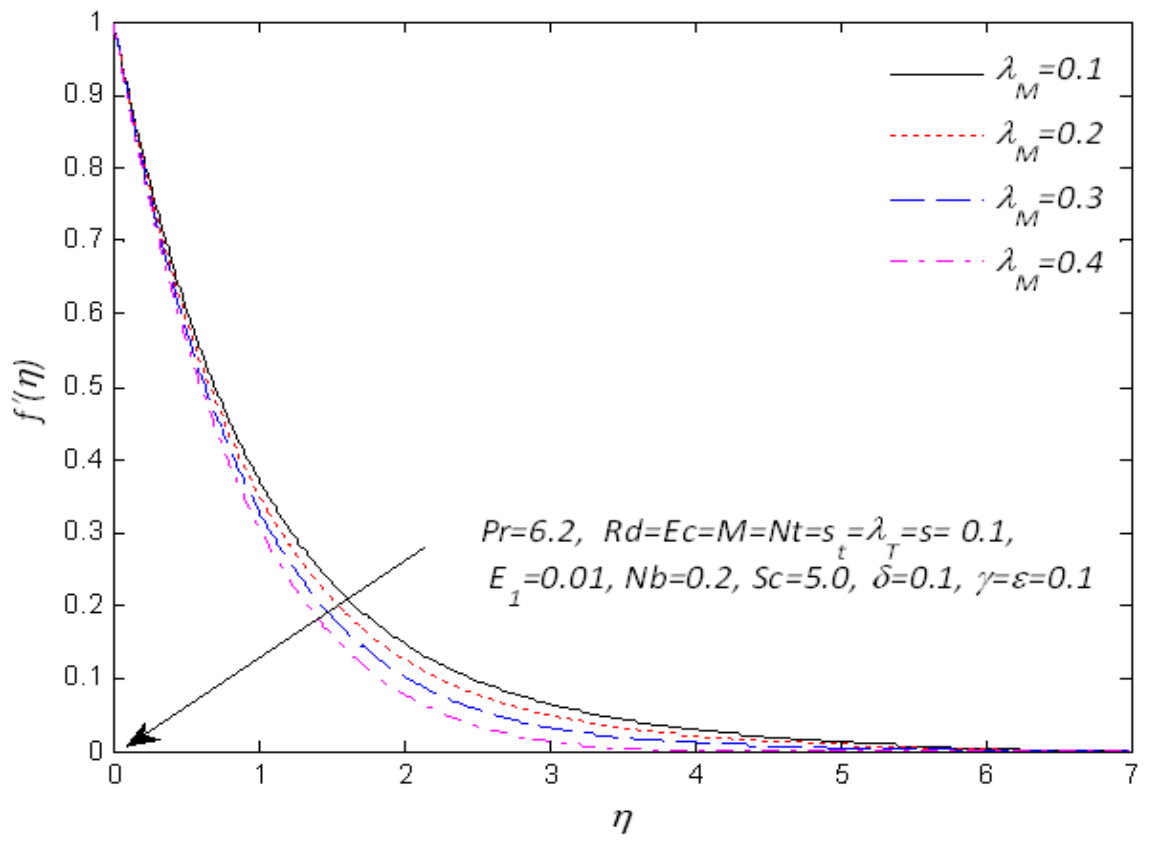

Figure 7: Velocity Profile for Varying $\lambda_{M}$ 
of temperature profile. Increasing the thermal radiation parameter implies that the absorption coefficient reduces. Thus temperature field increases. In Fig. 9 is the influence of Eckert number $E c$ on the non-dimensional temperature profile $\theta(\eta)$. It is perceiving that temperature is an increasing function of the Eckert number. The Eckert number stands for the ratio of the kinetic energy to enthalpy. For an increase in Eckert number, kinetic energy rises which leads to enhancement in the nanofluid temperature and thermal layer thickness. As the effect of thermal stratification $s_{t}$ on the non-dimensional temperature is displayed in Fig. 10. It is witnessed that the temperature is reduced with an increase in thermal stratification parameter. The prescribed surface temperature condition can be attained when $s_{t}=0$. Moreso, higher values of $s_{t}$ pointers lower nanofluid temperature and thinner thermal layer thickness. Fig. 11 illustrate the variation of heat generation/absorption $\varepsilon$ on non-dimensional temperature profile $\theta(\eta)$. Here $\varepsilon>0$ corresponds to heat generation and $\varepsilon<0$ leads to heat absorption. Noted that temperature profile and thickness of thermal layer are advanced for the heat generation in contrast to the heat absorption. The temperature and thickness of thermal layer rise when heat generation parameter increases while a reverse effect is witnessed for heat absorption case. Clearly, heat generation process more heat is produced which leads to the development of temperature field. In Fig. 12 disclosed the effect of thermal convective parameter $\lambda_{T}$ on the non-dimensional nanofluid temperature profile $\theta(\eta)$. The thermal convective parameter for heat transfer proves the relative impact of the thermal buoyancy force to the viscous momentum force in the boundary layer. It is spotted that there is a decay in the nanofluid temperature as result of an improvement in the viscous momentum force. Figs. 13 and 14 displayed the effects of nanoparticles parameters on the temperature profiles. Temperature field enhances and thermal boundary layer becomes thicker as thermophoretic and Brownian motion effect rises. The behavior of thermophoretic force ensure that the nanoparticles close the hot surface circulate at random towards the quiescent fluid at the ambient, which finally increases the thermal energy. It is interesting to note that the temperature and thermal boundary layer thickness are increasing function of Brownian motion and thermophoresis parameters. Thus one expects thermal boundary layer to become thicker in the presence of thermophoretic effect.

In Fig. 15 depicts the variation of Brownian motion parameter $\mathrm{Nb}$ on the non-dimensional nanoparticle concentration profile $\phi(\eta)$. In this Fig. higher values of Brownian motion parameter relate to the thinner thickness of the nanoparticles concentration layer becomes and lower nanoparticles concentration field. As detected in the nanofluid motion, as results of the presence of nanoparticles, the Brownian motion occurred and with an upsurge in the Brownian motion parameter, the Brownian motion is exaggerated and therefore the nanoparticles concentration layer thickness drops. Variation of thermophoresis parameter $N t$ on nanoparticles concentration profile $\phi(\eta)$ is sketched in Fig. 16. Both nanoparticles concentration profile and corresponds thickness are boosted for cumulative values of thermophoresis parameter. Fig. 17 displays that an increase in Schmidt number $S c$ amounted to a diminution in nanoparticles concentration profile $\phi(\eta)$. Schmidt number has an opposite bond with the Brownian diffusion coefficient. Higher values of Schmidt number associates to a fragile Brownian diffusion coefficient, and consequently drop in nanoparticles concentration profile. Fig. 18 shows the effects of mass convective parameter $\lambda_{M}$ on the nanoparticle concentration profile $\phi(\eta)$. The nanoparticle concentration decreases as results of an augmentation in the buoyancy force. The nanoparticle profile reaches a distinctive highest values closely to the stretching sheet. It is noticed that the nanoparticle concentration reduces with increasing values of convective parameter for mass 


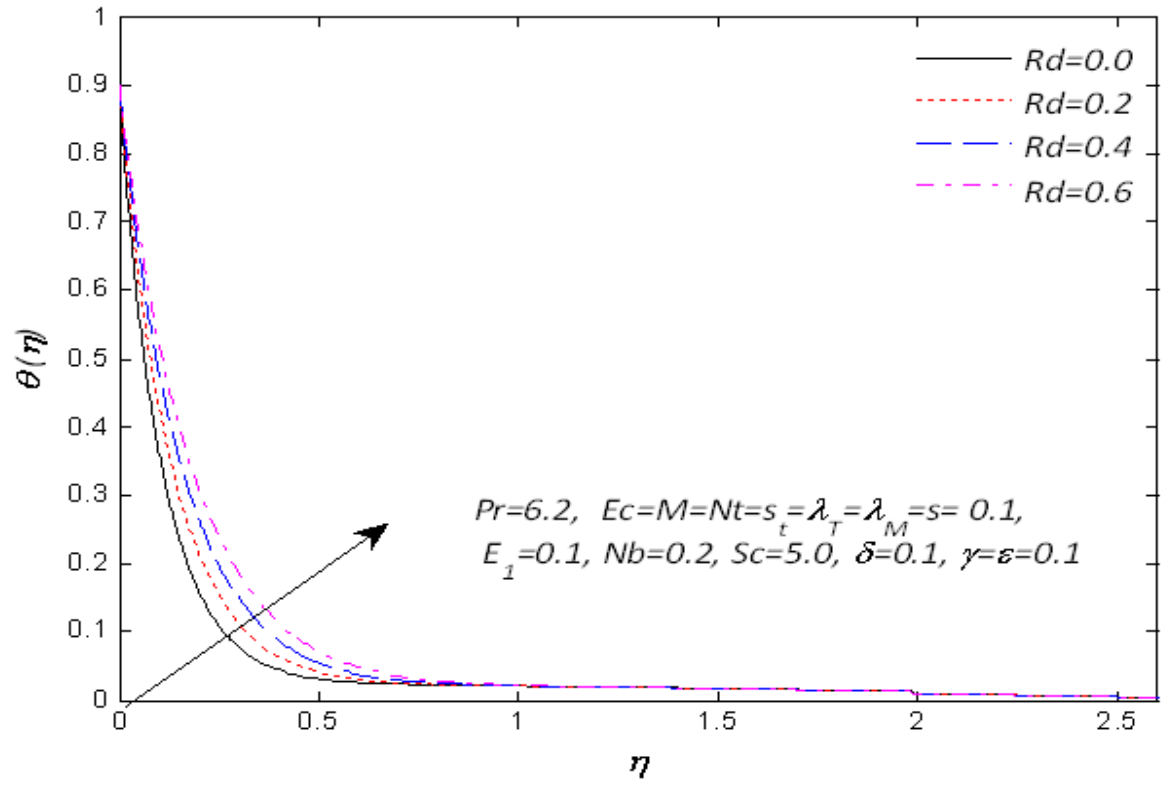

Figure 8: Temperature Profile for Varying $R d$

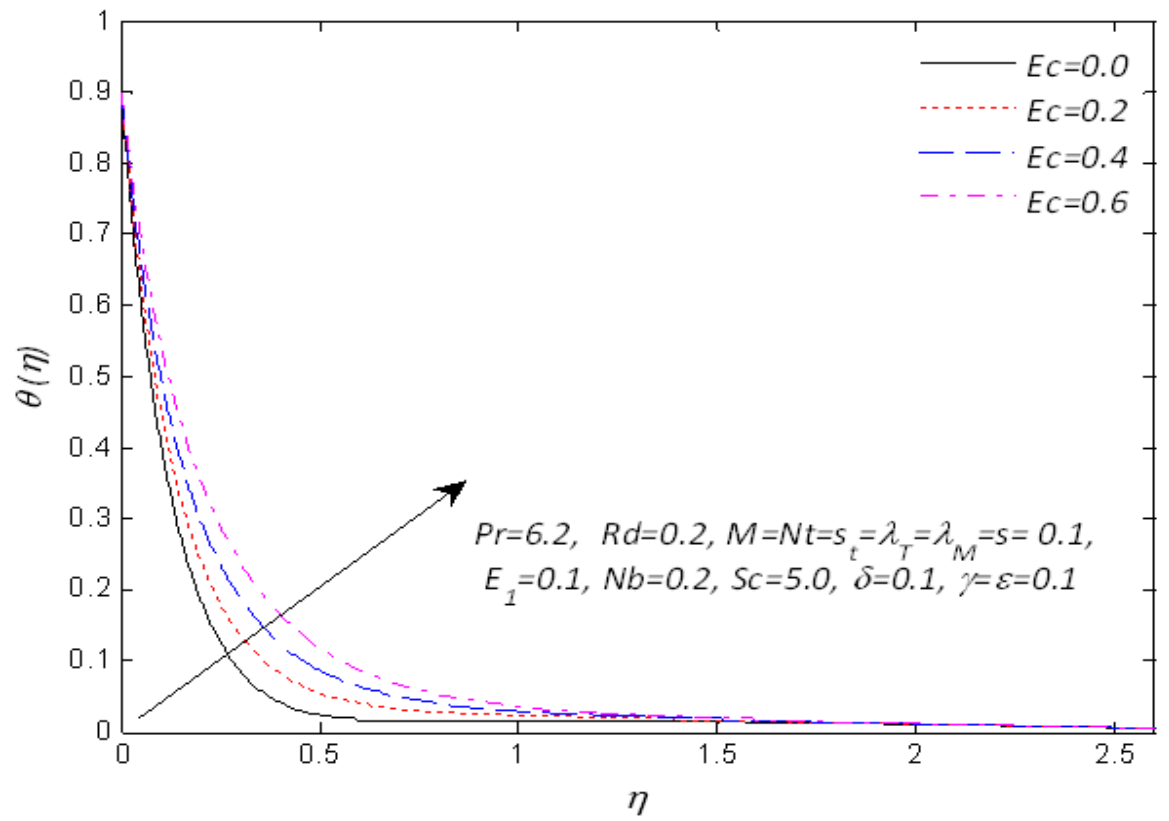

Figure 9: Temperature Profile for Varying $E c$ 


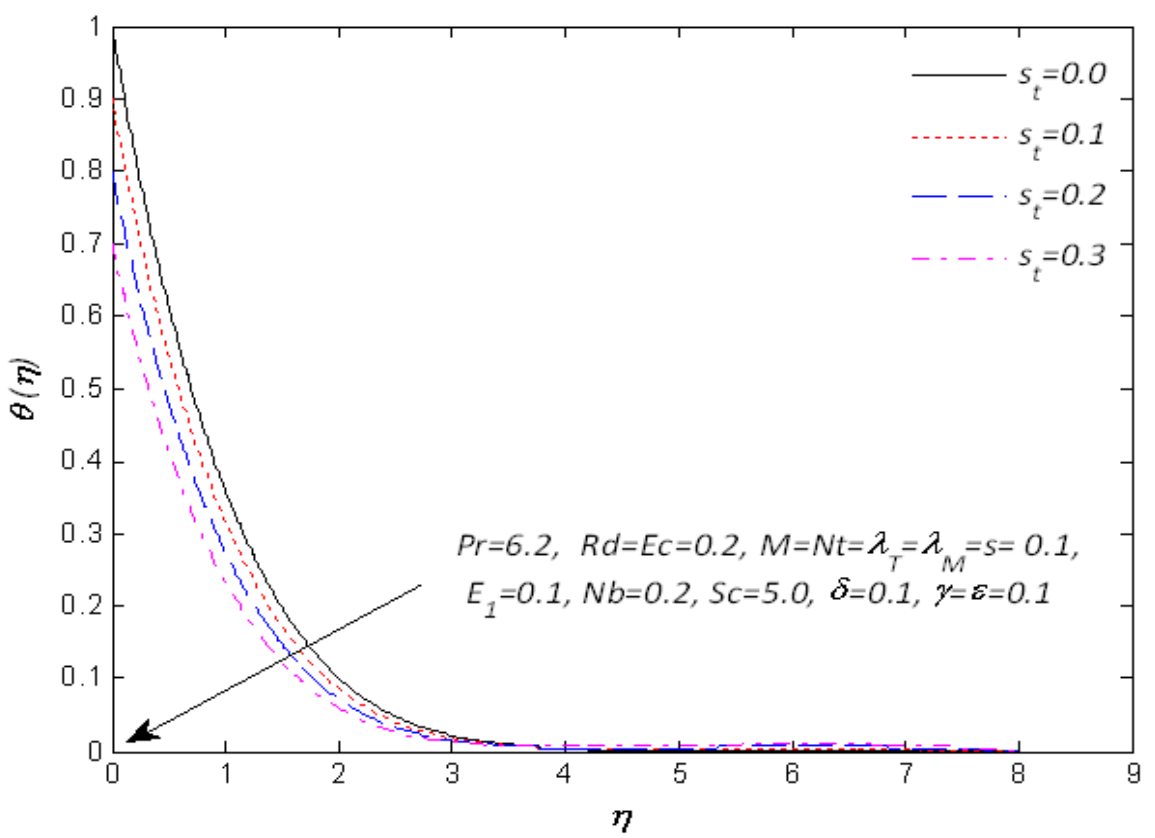

Figure 10: Temperature Profile for Varying $s_{t}$

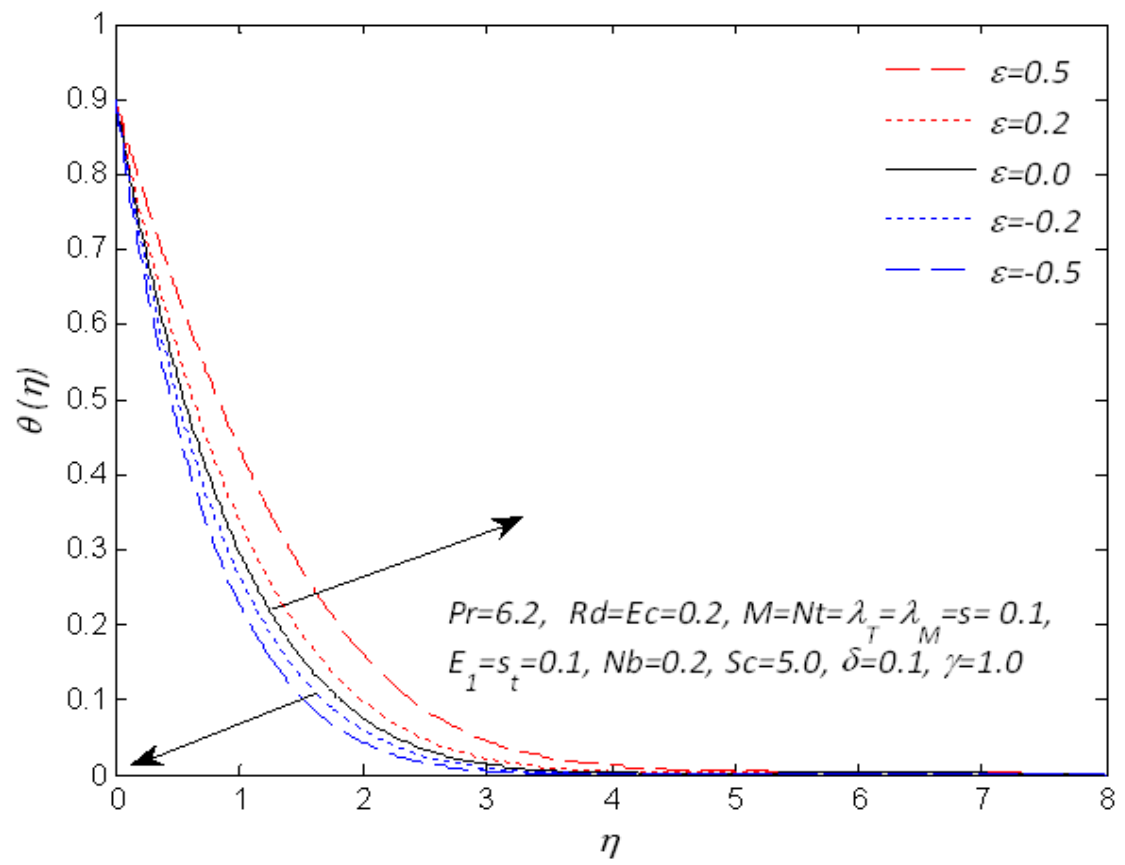

Figure 11: Temperature Profile for Varying $\varepsilon$ 


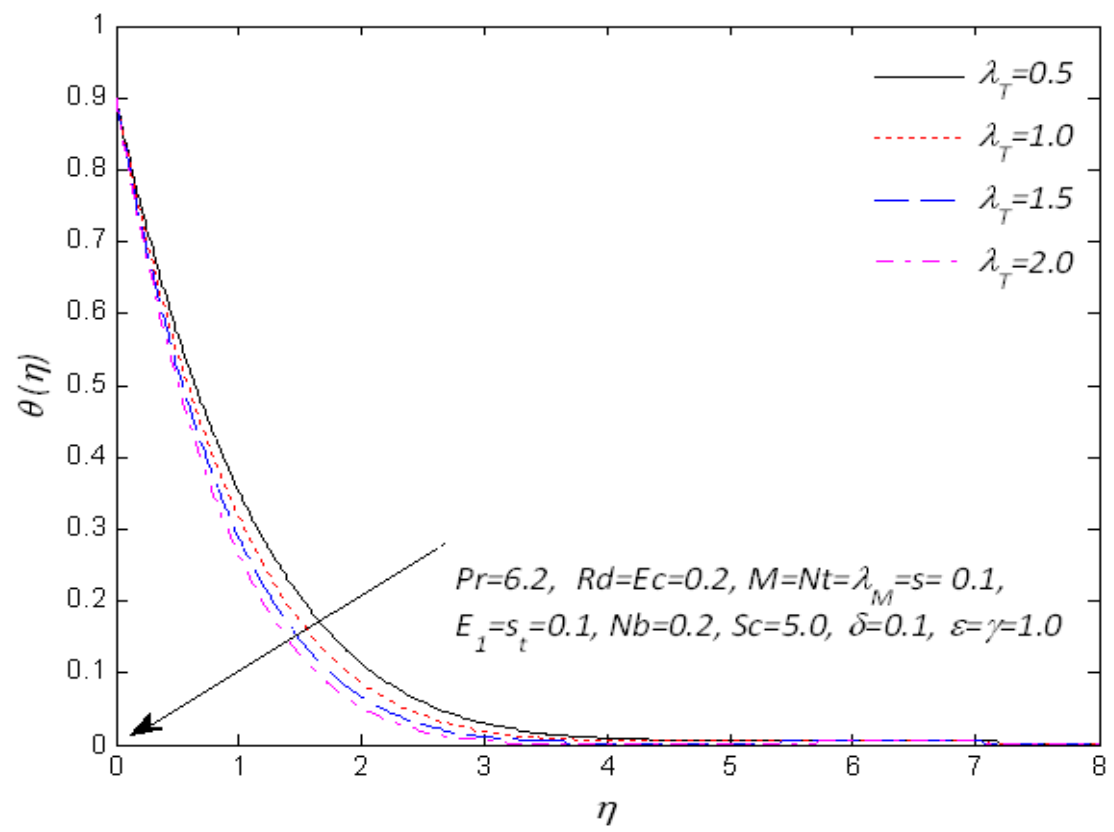

Figure 12: Temperature Profile for Varying $\lambda_{T}$

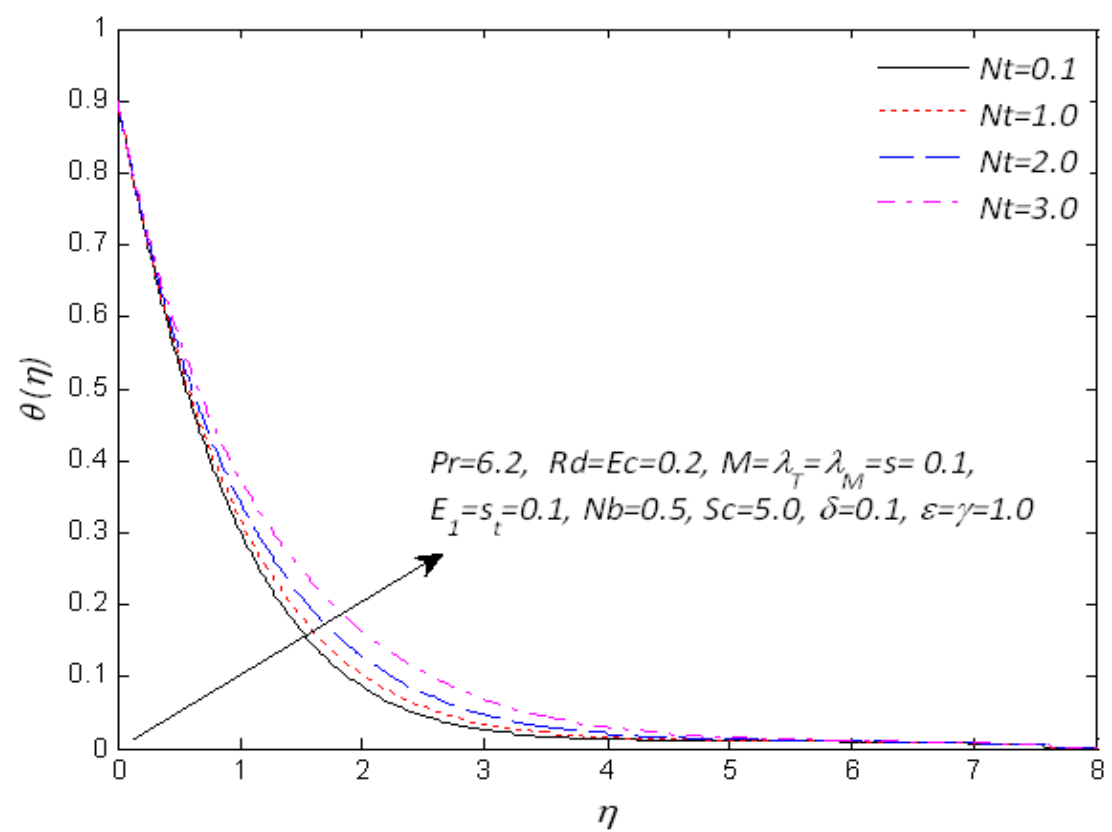

Figure 13: Temperature profile for varying $N t$ 


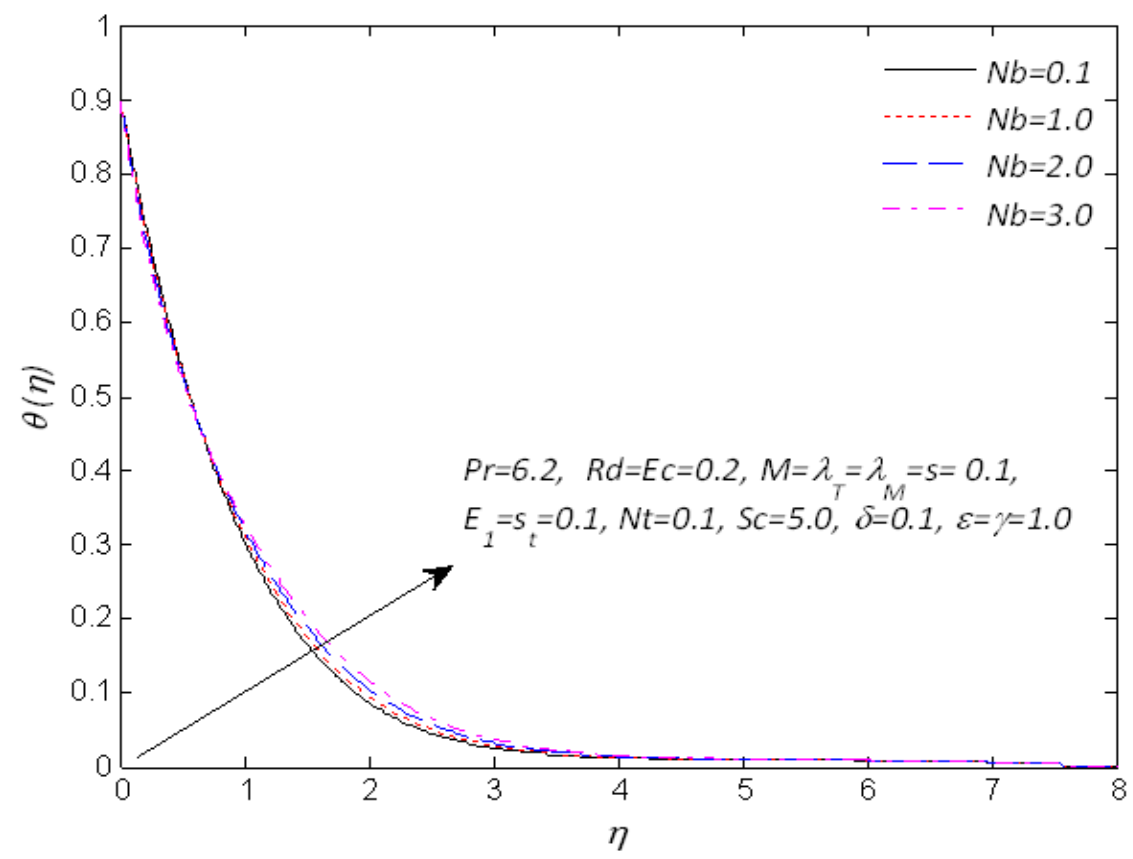

Figure 14: Temperature Profile for Varying $N b$

transfer. Fig. 19 portrays the effect of chemical reaction parameter on the concentration profile $\phi(\eta)$. It is evident that the fluid concentration losses with an intensification in the destructive chemical reaction parameter $(\gamma>0)$. Larger values of chemical reaction parameter associated with a higher rate of destructive chemical reaction which tends to destroy (dissipates) the fluid type strongly. Consequently, concentration profile drops.

The effects of ratio magnetic field and suction versus thermal convective parameter, electric field alongside with heat generation and absorption versus mass convective parameter on skinfriction coefficient are graphically demonstrated through Figures 20 and 21. It is understood from these illustrations that the skin friction and hence the corresponding wall shear stress gets enhanced their values with increase in magnetic field and suction parameters as well as heat absorption, conversely for the case with electric field, heat generation, thermal and mass convective parameters. In Figures 22 and 23, the reduced Nusselt number versus the nanoparticles parameters are plotted with the variations of thermal radiation and thermal stratification, as well as Eckert number, generative and destructive chemical reaction. For greater the radiative heat transfer, and thermal stratification, the lower the heat transfer rate at the surface turns out to reacts. For the case of viscous dissipation and thermophoretic parameters, as well as generative and destructive chemical reactions behaves in opposite manner. The Nusselt number is independent of the thermophoresis Brownian motion parameter which is being controlled at the wall with nanoparticle concentration and field. As a result the heat transfer rate is decreasing function of thermal radiation and viscous dissipation, it increases destructive chemical reaction when is increased. 


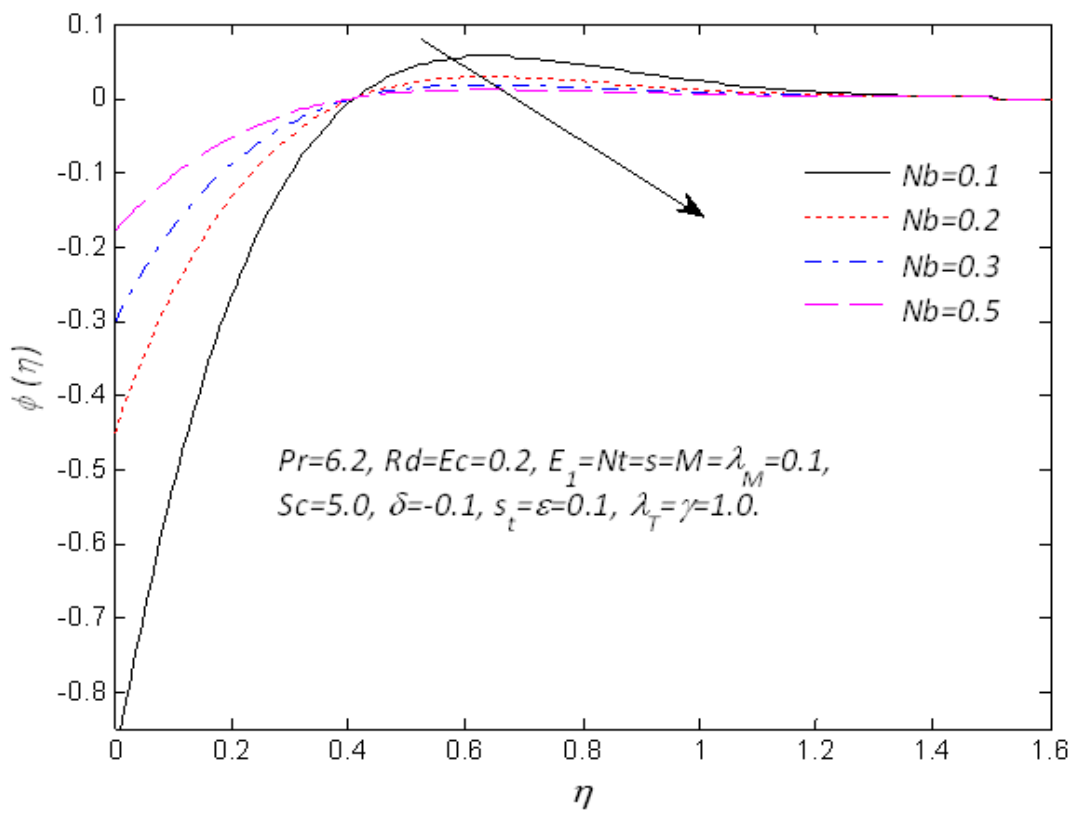

Figure 15: Concentration Profile for Varying $\mathrm{Nb}$

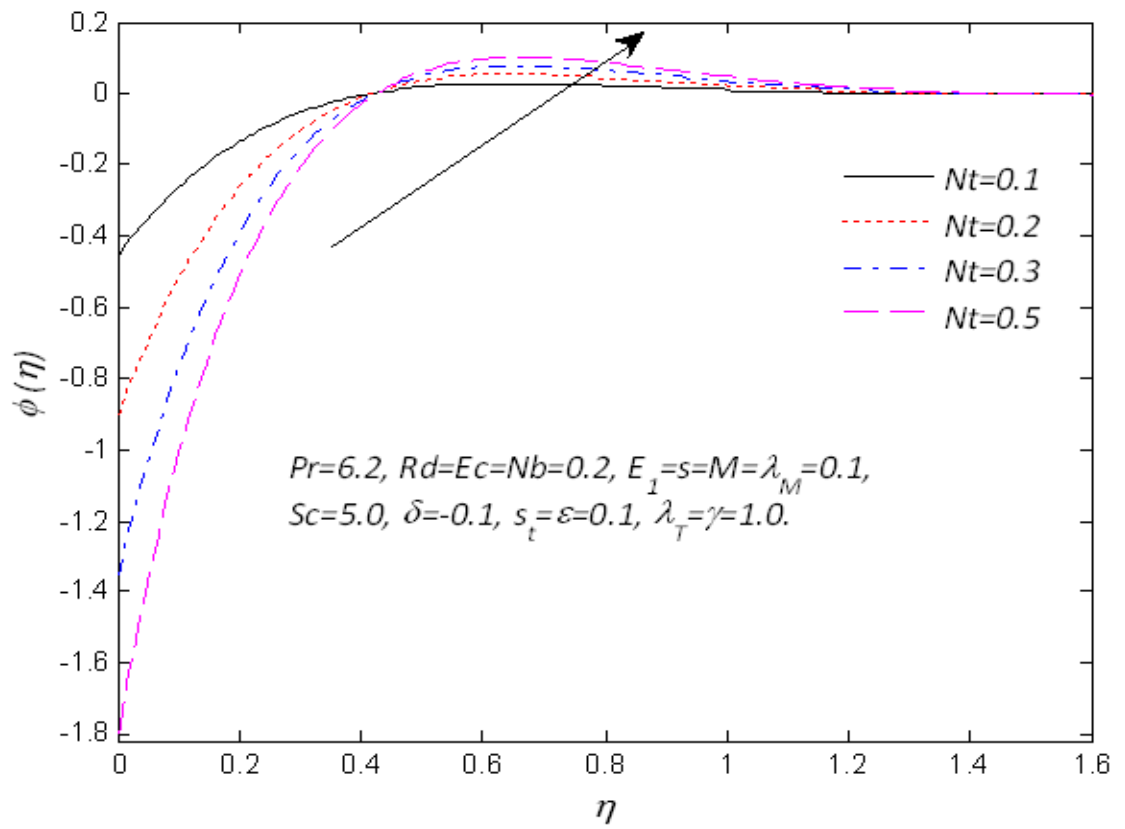

Figure 16: Concentration Profile for Varying $N t$ 


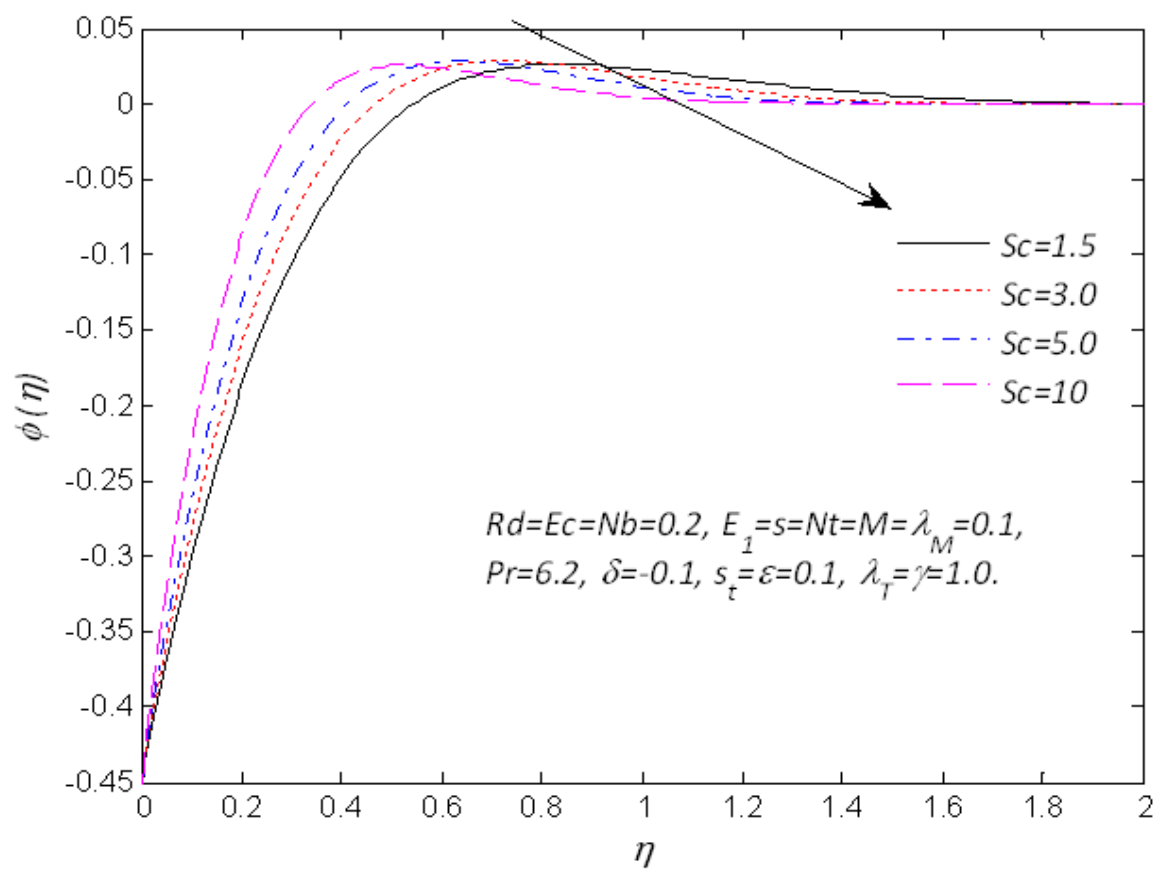

Figure 17: Concentration Profile for Varying $S c$

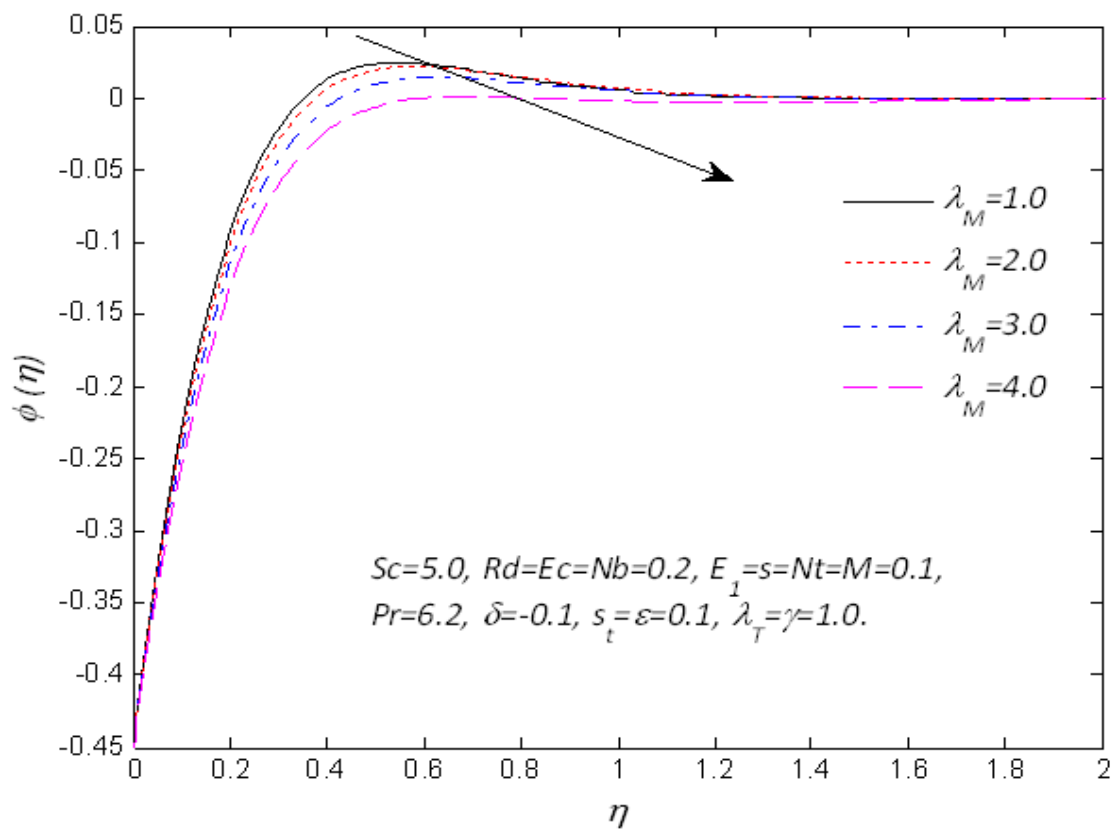

Figure 18: Concentration Profile for Varying $\lambda_{M}$ 


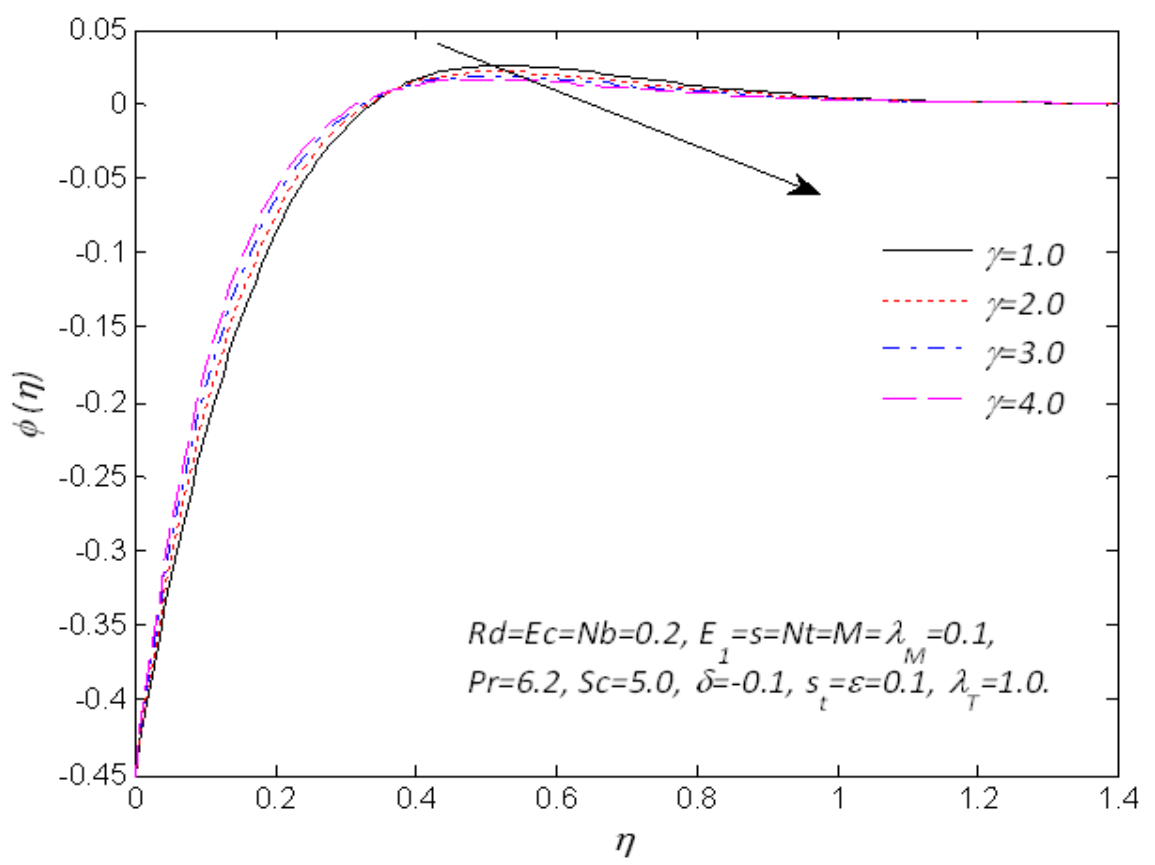

Figure 19: Concentration Profile for Varying $\gamma$

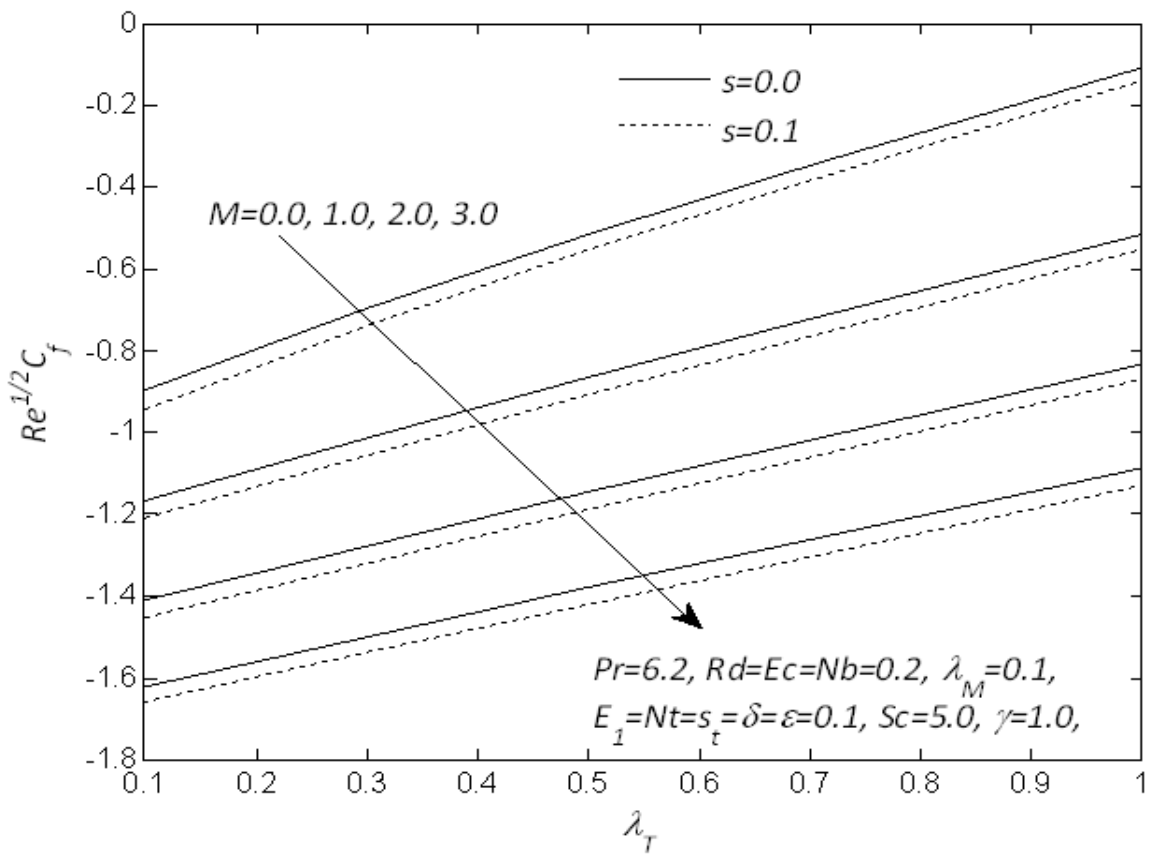

Figure 20: Skin Friction for Varying $M$ 


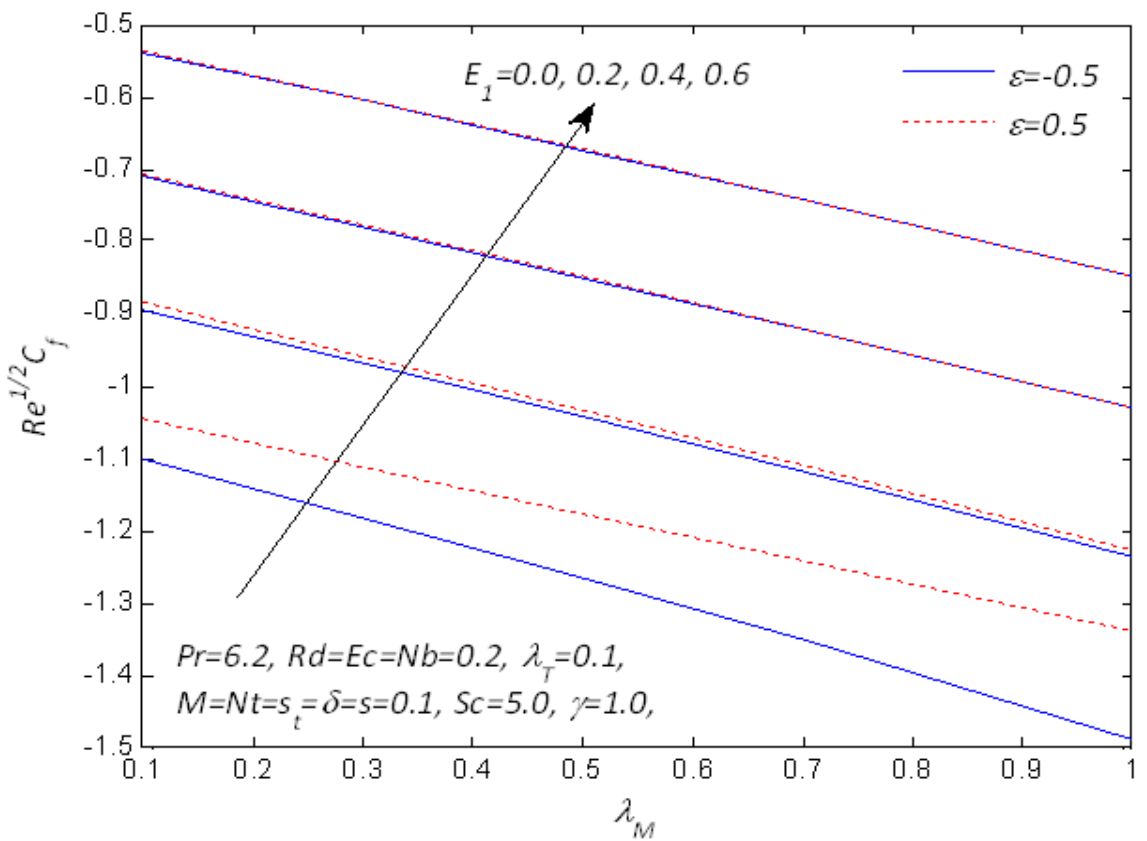

Figure 21: Skin Friction for Varying $E_{1}$

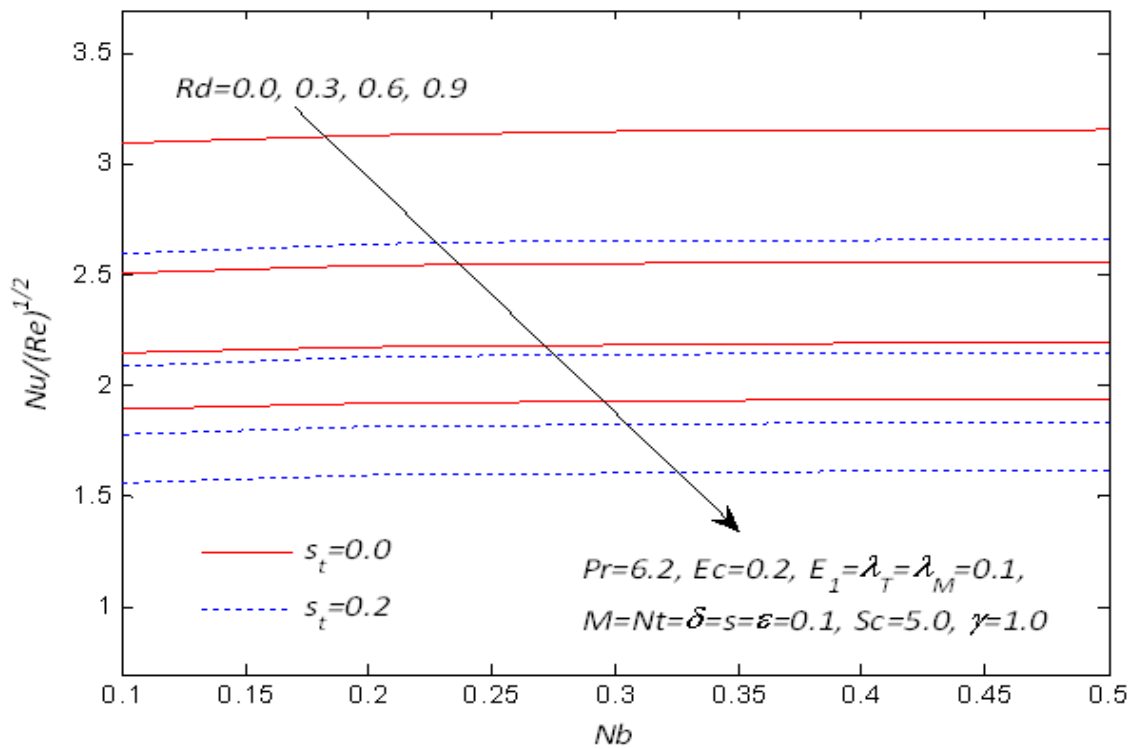

Figure 22: Nusselt Number for Varying $R d$ 


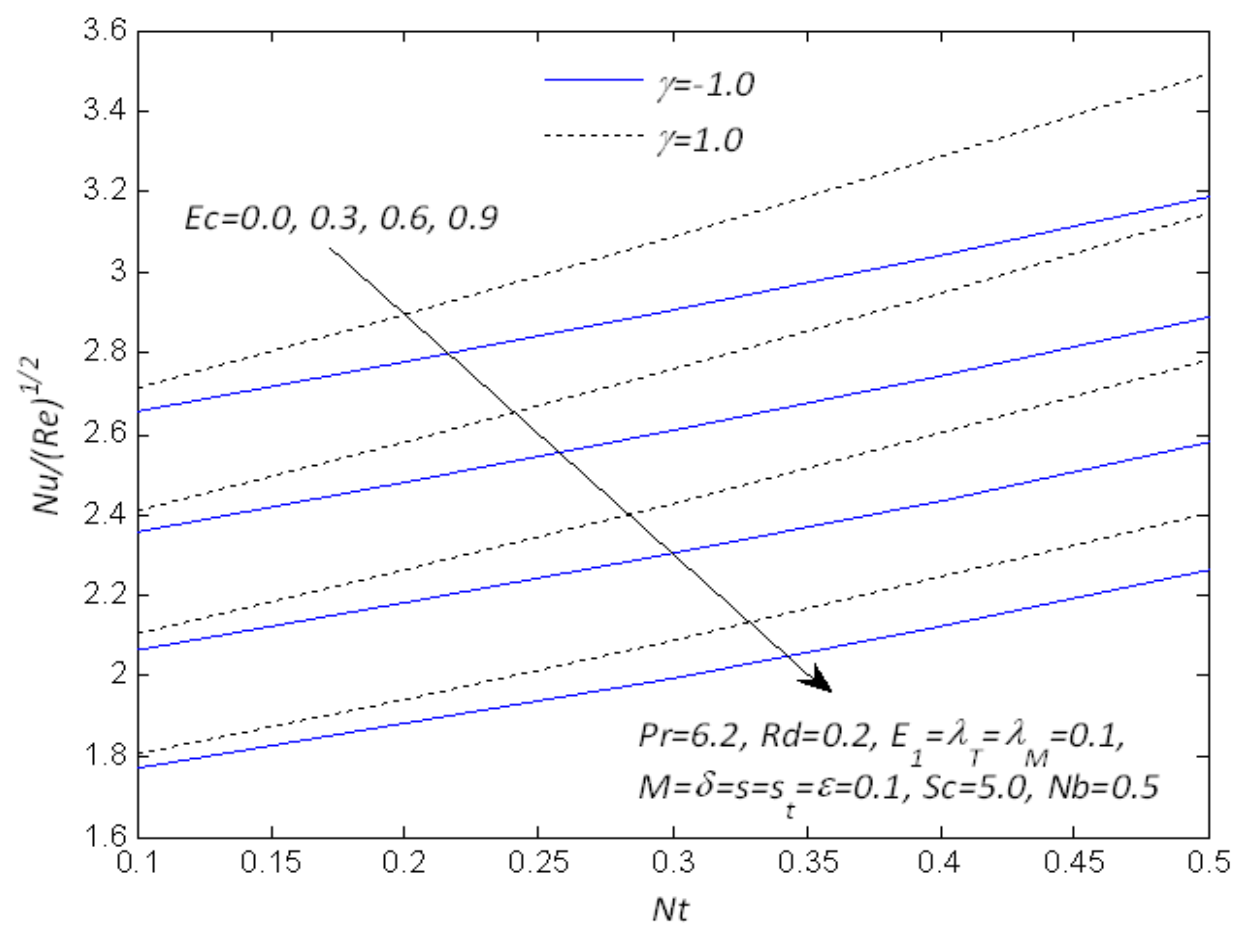

Figure 23: Nusselt Number for Varying Ec

\section{Final Remarks}

In this work, the thermal stratification and heat generation/absorption analysis has been conducted to investigate the electrical unsteady magnetohydrodynamic (MHD) natural convection flow and heat transfer in the presence of thermal radiation, viscous dissipation and chemical reaction of nanofluid over a permeable stretching sheet. The effects of pertinent parameters on two-dimensional flow characteristics and heat transfer are discussed numerically. The main conclusion of the study are presented as:

(1) Velocity profile augmentation for higher for larger values of the electric field but decreases with a magnetic field. Rise in thermal convective parameter leads to lower temperature and high nanofluid velocity flow.

(2) Effects of heat generation/absorption and suction/injection in terms of magnetic and electric fields are qualitatively opposite for temperature and velocity. Larger values of thermal stratification cause a diminution in temperature profile, and prescribed surface temperature condition is attained when $s_{t}=0$

(3) Nanoparticles concentration profile is developed for larger values of thermophoresis parameter while the opposite behavior is noticed for Brownian motion parameter.

(4) The skin friction coefficient upsurges with magnetic field $M$, suction $s$, and unsteadiness $\delta$ parameters, whereas it reductions with electric field $E_{1}$ parameter. 


\section{Acknowledgements}

The authors would like to acknowledge Ministry of Higher Education and Research Management Centre, UTM for the financial support through GUP with vote number 11H90, Flagship vote number 03G50, 13H28 and 03G53 for this research. Also, the authors sincere thanks the honorable referees and the editor for their valuable comments and suggestions to improve the quality of the paper.

\section{References}

[1] Choi, S., Enhancing thermal conductivity of fluids with nanoparticles. ASME-PublicationsFed. 1995. 231: 99-106.

[2] Kasaeian, A., Daneshazarian, R., Mahian, O., Kolsi, L., Chamkha, A. J., Wongwises, S., and Pop, I. Nanofluid flow and heat transfer in porous media: A review of the latest developments. International Journal of Heat and Mass Transfer. 2017. 107: 778-791.

[3] Qasim, M., Khan, Z. H., Lopez, R. J., and Khan, W. A. Heat and mass transfer in nanofluid thin film over an unsteady stretching sheet using Buongiorno's model. Eur. Phys. J. Plus. 2016. 16: 131.

[4] Sheikholeslami, M. and Ganji, D. Nanofluid convective heat transfer using semi analytical and numerical approaches: a review. Journal of the Taiwan Institute of Chemical Engineers. 2016. 65: 43-77.

[5] Buongiorno, J., Convective transport in nanofluids. Journal of Heat Transfer. 2006. 128(3): $240-250$.

[6] Daniel, Y. S., Aziz, Z. A., Ismail, Z., and Salah, F Effects of thermal radiation, viscous and Joule heating on electrical MHD nanofluid with double stratification. Chinese Journal of Physics. 2017. 55(3): 630-651.

[7] Nayak, M. K., Akbar, N. S., Tripathi, D., Khan, Z. H., and Pandey, V. S. MHD 3D free convective flow of nanofluid over an exponentially stretching sheet with chemical reaction. Advanced Powder Technology. 2017. 28(9): 2159-2166.

[8] Sheikholeslami, M. and Rokni, H. B. Nanofluid two phase model analysis in existence of induced magnetic field. International Journal of Heat and Mass Transfer. 2017. 107: 288-299.

[9] Sheikholeslami, M. and Rokni, H. B. Effect of melting heat transfer on nanofluid flow in the presence of a magnetic field using the Buongiorno Model. Chinese Journal of Physics. 2017. 55(4): 1115-1126..

[10] Reddy, N. and Reddy, K. J. Radiation and heat source effects on MHD stagnation point flow of chemically reacting Casson nanofluid over a nonlinear stretching sheet with velocity slip and convective boundary conditions. IJMCA. 2017. 5(1): 001-012.

[11] Hayat, T., Ullah, I., Alsaedi, A., and Farooq, M. MHD flow of Powell-Eyring nanofluid over a non-linear stretching sheet with variable thickness. Results in Physics. 2017. 7: 189-196.

[12] Daniel, Y. S., Aziz, Z. A., Ismail, Z. and Salah, F. Entropy analysis in electrical magnetohydrodynamic (MHD) flow of nanofluid with effects of thermal radiation, viscous dissipation, and chemical reaction. Theoretical and Applied Mechanics Letters. 2017. 7(4): 235-242. 
[13] Daniel, Y. S. Steady MHD Laminar Flows and Heat Transfer Adjacent to Porous Stretching Sheets using HAM. American Journal of Heat and Mass Transfer. 2015. 2(3): 146-159.

[14] Daniel, Y. S. Presence of heat generation/absorption on boundary layer slip flow of nanofluid over a porous stretching sheet. American J. of Heat and Mass Transfer. 2015. 2(1): 15 .

[15] Daniel, Y. S. Laminar Convective Boundary Layer Slip Flow over a Flat Plate using Homotopy Analysis Method. Journal of The Institution of Engineers (India): Series E. 2016. 97(2): 115-121.

[16] Daniel, Y. S. MHD Laminar Flows and Heat Transfer Adjacent to Permeable Stretching Sheets with Partial Slip Condition. Journal of Advanced Mechanical Engineering. 2017. 4(1): 1-15.

[17] Hsiao, K. L. Stagnation electrical MHD nanofluid mixed convection with slip boundary on a stretching sheet, Applied Thermal Engineering. 2016. 98: 850-861.

[18] Uddin, M. J., Bég, O. A. and Ismail, A. I. Radiative convective nanofluid flow past a stretching/shrinking sheet with slip effects. Journal of Thermophysics and Heat Transfer. 2015. 29(3): 513-523.

[19] Zhang, C., Zheng, L., Zhang, X., and Chen, G. MHD flow and radiation heat transfer of nanofluids in porous media with variable surface heat flux and chemical reaction. Applied Mathematical Modelling. 2015. 39(1): 165-181.

[20] Ahmad, S., Vieru, D., Khan, I. and Shafie, S. Unsteady magnetohydrodynamic free convection flow of a second grade fluid in a porous medium with ramped wall temperature. PloS One. 2014. 9(5): e88766.

[21] Haddad, Z., Abu-Nada, E., Oztop, H. F. and Mataoui, A. Natural convection in nanofluids: are the thermophoresis and Brownian motion effects significant in nanofluid heat transfer enhancement? International Journal of Thermal Sciences. 2012. 57: 152-162.

[22] Hayat, T., Shah, F., Alsaedi, A. and Khan, M. I. Development of homogeneous/heterogeneous reaction in flow based through non-Darcy Forchheimer medium. Journal of Theoretical and Computational Chemistry. 2017: 1750045.

[23] Hayat, T., Imtiaz, M. and Alsaedi, A. Unsteady flow of nanofluid with double stratification and magnetohydrodynamics. International Journal of Heat and Mass Transfer. 2016. 92: 100-109.

[24] Hayat, T., Waqas, M., Khan, M. I. and Alsaedi, A., Analysis of thixotropic nanomaterial in a doubly stratified medium considering magnetic field effects. International Journal of Heat and Mass Transfer. 2016. 102: 1123-1129.

[25] Besthapu, P., Haq, R. U., Bandari, S. and Al-Mdallal, Q. M. Mixed convection flow of thermally stratified MHD nanofluid over an exponentially stretching surface with viscous dissipation effect. Journal of the Taiwan Institute of Chemical Engineers. 2017. 71: 307314.

[26] Abbasi, F., Shehzad, S., Hayat, T. and Ahmad, B. Doubly stratified mixed convection flow of Maxwell nanofluid with heat generation/absorption. Journal of Magnetism and Magnetic Materials. 2016. 404: 159-165. 
[27] Ganesh, N. V., Hakeem, A. A. and B. Ganga, Darcy-Forchheimer flow of hydromagnetic nanofluid over a stretching/shrinking sheet in a thermally stratified porous medium with second order slip, viscous and Ohmic dissipations effects. Ain Shams Engineering Journal. 2016. https://doi.org/10.1016/j.asej.2016.04.019

[28] Kuznetsov, A. and Nield, D. The Cheng-Minkowycz problem for natural convective boundary layer flow in a porous medium saturated by a nanofluid: a revised model. International Journal of Heat and Mass Transfer. 2013. 65: 682-685.

[29] Cebeci, T. and Bradshaw, P. Physical and Computational Aspects of Convective Heat transfer. New York: Springer Science \& Business. 1988 Media.

[30] Hayat, T., Shafiq, A. and Alsaedi, A. Effect of Joule heating and thermal radiation in flow of third grade fluid over radiative surface. Plos One. 2014. 9(1): e83153.

[31] Alsaedi, A., Khan, M. I., Farooq, M., Gull, N. and Hayat, T., Magnetohydrodynamic (MHD) stratified bioconvective flow of nanofluid due to gyrotactic microorganisms. Advanced Powder Technology. 2017. 28(1): 288-298.

[32] Daniel, Y. S. and Daniel, S. K. Effects of buoyancy and thermal radiation on MHD flow over a stretching porous sheet using homotopy analysis method. Alexandria Engineering Journal. 2015. 54(3): 705-712.

[33] Ibrahim, W. and Shankar, B. MHD boundary layer flow and heat transfer of a nanofluid past a permeable stretching sheet with velocity, thermal and solutal slip boundary conditions. Computers \& Fluids. 2013. 75: 1-10.

[34] Mabood, F., Khan, W. and Ismail, A. M. MHD boundary layer flow and heat transfer of nanofluids over a nonlinear stretching sheet: a numerical study. Journal of Magnetism and Magnetic Materials. 2015. 374: 569-576.

[35] Makinde, O. and Animasaun, I. Thermophoresis and Brownian motion effects on MHD bioconvection of nanofluid with nonlinear thermal radiation and quartic chemical reaction past an upper horizontal surface of a paraboloid of revolution. Journal of Molecular Liquids. 2016. 221: 733-743. 